\title{
The Skill Complementarity of Broadband Internet*
}

\author{
Anders Akerman ${ }^{\dagger} \quad$ Ingvil Gaarder Magne Mogstad $^{\ddagger}$
}

This Version: October 2013

\begin{abstract}
Does adoption of broadband internet in firms enhance labor productivity and increase wages? And is this technological change skill biased or factor neutral? We exploit rich Norwegian data with firm-level information on value added, factor inputs and broadband adoption to answer these questions. We estimate production functions where firms can change their technology by adopting broadband internet. A public program with limited funding rolled out broadband access points, and provides plausibly exogenous variation of broadband adoption in firms. This enables us to address endogeneity of broadband adoption and examine how it shifts the production technology and changes the productivity and labor outcomes of different types of workers. We find that broadband adoption favors skilled labor by increasing its relative productivity. The increase in productivity of skilled labor is especially large for college graduates in fields such as science, technology, engineering and business. By comparison, broadband internet is a substitute for workers without high school diploma, lowering their marginal productivity. Consistent with the estimated changes in labor productivity, wage regressions show the expansion of broadband internet improves (worsens) the labor outcomes of skilled (unskilled) workers. We explore several possible explanations for the skill bias of broadband internet. We find suggestive evidence that broadband internet complements skilled workers in executing nonroutine abstract tasks, and substitutes for unskilled workers in performing routine tasks. When we use our production function estimates to construct measures of firm level productivity, we find that broadband internet accounts for a few percent of the standard deviation in total factor productivity across firms. Taken together, our findings have important implications for the ongoing policy debate over government investment in broadband infrastructure to encourage productivity and wage growth.
\end{abstract}

Keywords: Broadband internet, labor productivity, tasks, technological change, skill bias JEL codes: J23; J24; J31; O33

\footnotetext{
*Thanks to Jerome Adda, Ingvild Almaas, Russel Cooper, David Green, and Morten Ravn for helpful comments and suggestions.

†Stockholm University. E-mail: anders.akerman@gmail.com

${ }^{\ddagger}$ European University Institute. Email: ingvil.gaarder@gmail.com

$\S$ University College London \& Statistics Norway. Email: magne.mogstad@gmail.com
} 


\section{Introduction}

Economists and policymakers are keenly interested in understanding the productivity and labor market effects of the advancements in information and communication technology (ICT). Many have argued that these technological changes were behind the resurgence in U.S. productivity growth since the late 1990s, and that investments in ICT are important in explaining labor productivity patterns across multiple industries and countries 11 Recently, policymakers have pointed to broadband internet as a key productivity enhancing factor, calling for public funding to roll out broadband infrastructure. $2^{2}$ While government agencies are projecting broadband penetration rates to be important for productivity and job creation, there is little scientific evidence to substantiate these claims.$^{3}$

Estimating how adoption of new technology, such as broadband internet, affects productivity has proven difficult for several reasons. It is often difficult to access data on technology adoption which can be linked with firm-level information on value added and factor inputs. Another key challenge is the likelihood that some determinants of production are unobserved to the econometrician but observed by the firm; if adoption of new technology depends on these determinants, then OLS estimates of production functions will be biased. On top of this, the use of inputs such as capital and labor could also be correlated with technology adoption and unobserved productivity, and therefore create bias in OLS estimates. These empirical challenges have meant that existing research has largely focused on demonstrating positive associations of ICT with productivity. Draca, Sadun, and Van Reenen (2007), in their Handbook of Information and Communication Technologies chapter, review the literature carefully and conclude that "none of the literature has produced convincing evidence of a causal impact of ICT on productivity, for example by analyzing a natural experiment".

In this paper, we examine how the adoption of new technology in firms shifts their production technology and changes the productivity and labor outcomes of different types of workers. Our context is the adoption of broadband internet in Norwegian firms over the

\footnotetext{
${ }^{1}$ The evidence is reviewed in Draca, Sadun, and Van Reenen (2007), Oliner, Sichel, and Stiroh (2007), Jorgenson, Ho, and Stiroh (2008), and Syverson (2011). See also Bloom, Sadun, and Van Reenen (2012).

2President Obama's campaign in 2008 promised that "every American should have the highest form of broadband access". Later, he called on Congress to approve funding for rolling out broadband to unserved and underserved areas, arguing that increased broadband spending will keep America competitive while also creating new jobs. In the UK, former Prime Minister Gordon Brown compared the expansion of broadband infrastructure to "the roads and the bridges and the railways that were built in previous times to stimulate the economy".

${ }^{3}$ In 2008, the U.S. Commissioner of Federal Communications Commission stated that "Affordable broadband would quickly add $\$ 500$ billion to the U.S. Economy and create 1.2 million jobs". Projections from the U.S. Bureau of Economic Analysis suggest that for every $\$ 1$ invested in broadband, the economy benefits nearly $\$ 3$. A notable example of research on this topic is Czernich, Falck, Kretschmer, and Woessmann (2011), who find positive association between broadband penetration and economic growth across OECD countries over time. Another example is Forman, Goldfarb, and Greenstein (2012), showing that internet investments correlate with wage and employment growth in some but not all U.S. counties.
} 
period 2001-2007.4 Norway is a small open economy with segmented local labor markets. Our analysis employs several data sources that we can link through unique firm and individual identifiers. Using firm-level information on value added, capital, labor by skill level and broadband adoption, we estimate production functions where firms can change their technology by adopting broadband internet.5 We complement these production function estimates with wage regressions which include interactions between skill levels and broadband internet.

As a source of exogenous variation in broadband adoption, we follow Bhuller, Havnes, Leuven, and Mogstad (forthcoming) in exploiting a public program aimed at ensuring broadband access at a reasonable price to all households throughout the country..$^{6}$ Because of limited funding, access to broadband was progressively rolled out, so that the necessary infrastructure (access points) was established in different municipalities at different times. We use this spatial and temporal variation in the availability of broadband across municipalities as an instrumental variable for adoption of broadband in firms. Our identification strategy - which controls for municipality (time and industry) fixed effects - is motivated by two features of the broadband program. First, most of the supply and demand factors tend to vary little over time. Second, the timing of the roll-out is unlikely to co-vary with the key correlates of productivity and labor outcomes. We demonstrate that the data is consistent with these program features, and further challenge the validity of the instrument by probing the stability of the estimates to alternative specifications, finding little cause for worry. Following Levinsohn and Petrin (2003), we also make sure that the results are robust to using intermediate inputs to proxy for unobserved productivity in the production function.

The main results of our analysis can be seen in Figure 1. This figure shows estimates of labor productivity and skill premium before and after the expansion of broadband internet, providing a visual representation of the reduced form of our econometric models. Time zero represents the year with the strongest growth in broadband coverage rate in a given municipality, after taking out municipality, industry and year fixed effects. In each time period, we estimate Cobb-Douglas production functions and wage regressions while controlling for municipality, industry and year fixed effects. The graphs suggest strong skill complementarity of broadband internet. The first (second) graph shows that the sharp rise in coverage rates from time -1 to time zero is associated with a substantial increase (decrease) in the output elasticity of (un)skilled labor. The third graph shows

\footnotetext{
${ }^{4}$ Throughout the paper, we focus on broadband internet, defined as internet connections with download speeds that exceed $256 \mathrm{kbit} / \mathrm{s}$. Before the expansion of broadband internet, all firms with a telephone connection would have dial-up access to internet, but limited to a bitrate of less than $56 \mathrm{kbit} / \mathrm{s}$. Broadband internet facilitated internet use without excessive waiting times.

${ }^{5}$ Throughout the paper, we follow the literature by referring to education and skills interchangeably; thus skilled refers to highly educated and unskilled refers to those with lower levels of education.

6 Bhuller, Havnes, Leuven, and Mogstad (forthcoming) use the roll-out of broadband internet to study how internet use affects sex crimes.
} 
Figure 1. Labor productivity and skill premium, pre and post expansion

(a) Output elasticity: Skilled labor

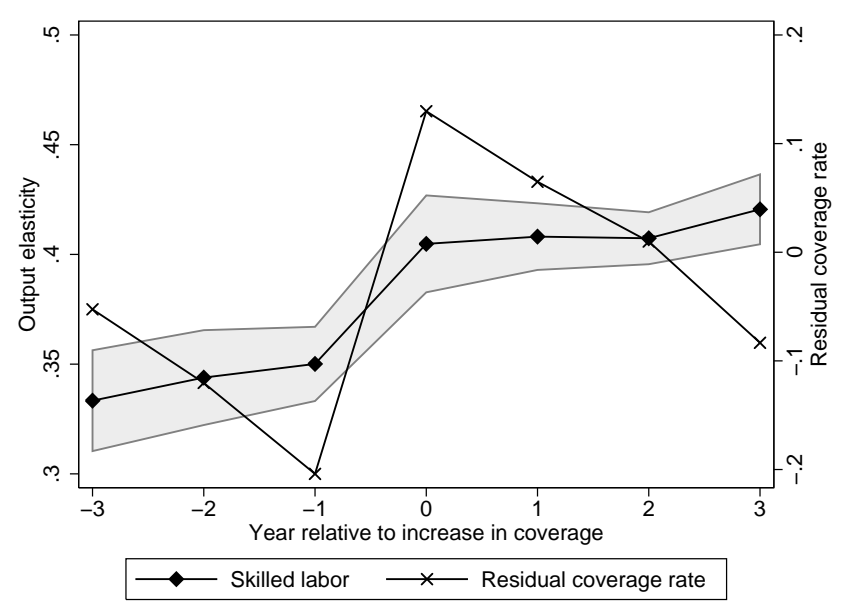

(b) Output elasticity: Unskilled labor

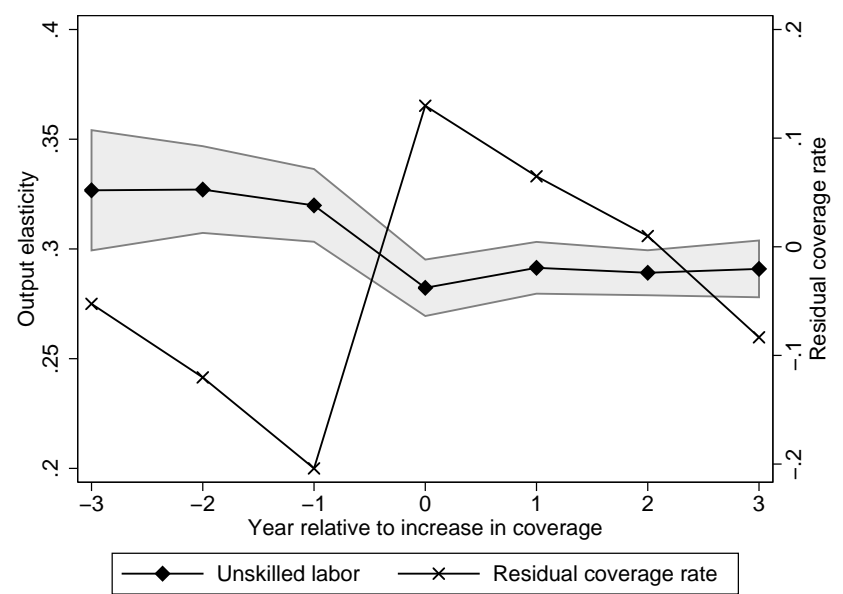

(c) Return to Skill: Hourly wage

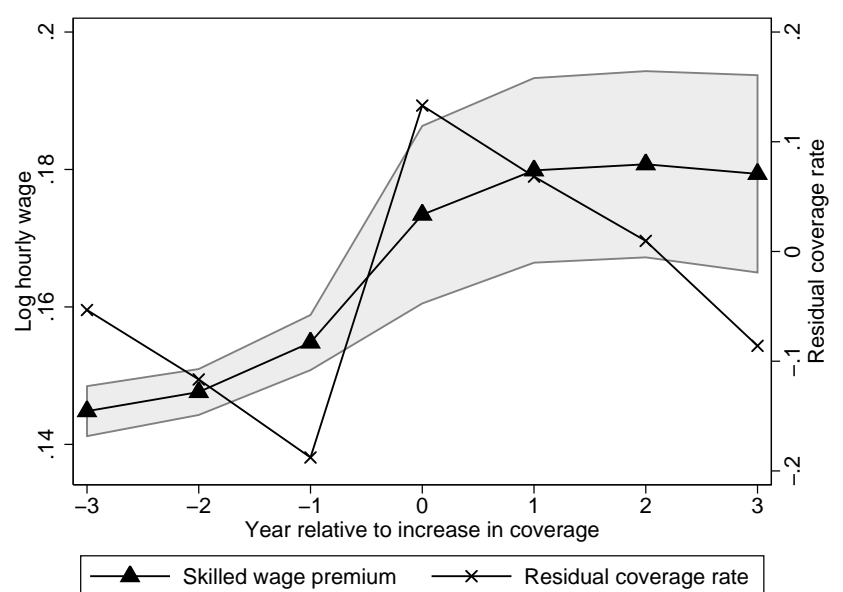

Note: Baseline samples of firms and workers during the period 2001-2007 (see Section 3 for details). Coverage rates are residuals from a regression of municipality-level broadband coverage on municipality, industry and year fixed effects. Time zero represents the year with the strongest growth in residual coverage rates in a given municipality. In each period, we estimate Cobb-Douglas production functions and wage regressions while controlling for municipality, industry and year fixed effects. Graphs (a) and (b) report period-specific OLS estimates of the output elasticity of skilled and unskilled labor. Graph (c) reports period-specific OLS estimates of log hourly wage on a dummy for skilled and controls for gender and potential experience. The grey areas show $95 \%$ confidence intervals. 
how relative wages of skilled workers increases after this rise in coverage rates.

Consistent with this reduced form evidence, the structural production function estimates show that broadband adoption in firms favors skilled labor by increasing its relative productivity. The estimated increase in productivity of skilled labor is especially large for workers with college degree in high return fields such as science, technology, engineering, and business. By comparison, broadband internet is a substitute for workers without high school diploma, lowering their marginal productivity. In line with the estimated changes in labor productivity, the wage regressions show that the expansion of broadband internet improves (worsens) the labor outcomes of (un)skilled workers. The gains are largest for college graduates in high return fields. When we use our production function estimates to construct measures of firm level productivity, we find that broadband internet accounts for a few percent of the standard deviation in total factor productivity across firms.

Our findings are consistent with the widespread view that ICT is complementary with human capital. Technological changes that reduce quality-adjusted ICT prices - such as the arrival of broadband internet - should therefore increase skill demand and returns to skill. While the labor market consequences of investments in computers and R\&D have been studied extensively $]^{7}$ we provide novel evidence on the skill bias of broadband adoption. We also show an important link between computerization and broadband adoption in firms: When broadband internet becomes available, it is not randomly adopted; instead, it is more quickly adopted in firms in which complementary factors are abundent, including computers and skilled workers. These findings conform to the predictions of a model of endogenous technology adoption where firms' choices reflect principles of comparative advantage (see e.g. Beaudry and Green, 2003, 2005; Beaudry, Doms, and Lewis, 2010). This pattern of broadband adoption illustrates that the estimated effects pertain to a subgroup of early adopters of broadband internet, and that we need to be cautious in extrapolating these local estimates to the longer-run impact of broadband adoption for the population of firms at large.

We further use the rich Norwegian data to explore possible mechanisms behind the skill bias of broadband adoption. We find two pieces of evidence against the hypothesis that our findings reflect changes in the demand for goods due to the expansion of broadband internet. First, we find no impact of broadband adoption on online sales or procurement. Second, when we look separately at firms in the tradeable sector where demand is given by the world market, we still find that broadband adoption in firms favors skilled labor by increasing its relative productivity. Our data is also at odds with broadband adoption coinciding with general technical upgrading in firms. Another possible mechanism receiving little support in data is that our findings are driven by changes in labor productivity and

\footnotetext{
${ }^{7}$ See e.g. Krueger (1993), Berman, Bound, and Griliches (1994), DiNardo and Pischke (1997), Autor, Katz, and Krueger (1998), Machin and Van Reenen (1998), Beaudry and Green (2003||2005) and Beaudry, Doms, and Lewis (2010). Acemoglu (2003), Bond and Van Reenen (2007) and Goldin and Katz (2007) provide recent reviews of the extensive literature on technology-skill complementarity.
} 
wages in firms directly affected by the expansion of broadband access, such as telecom firms or IT consultancy companies.

Instead, our findings are consistent with the task approach to skill biased technological change. Autor, Levy, and Murnane (2003) argue that ICT substitutes for workers in performing routine tasks - more amenable to automatization - and complements workers in executing problem-solving, complex communication, and information-intensive tasks (ofted called "nonroutine abstract tasks") 8 We first show that workers of different educational background indeed cluster disproportionately in occupations that require different tasks. In particular, college graduates tend to move into occupations that are pervasive at nonroutine abstract tasks, especially those with degrees in high return fields. By comparison, low educated workers are over-represented in occupations that involve relatively little nonroutine abstract tasks, but require more routine or manual tasks. Next, we estimate wage regressions which include interactions between broadband internet and the tasks performed in jobs rather than (or in addition to) the educational credentials of workers performing those jobs. These estimates suggest an important channel behind the skill bias of broadband internet is that it complements non-routine abstract tasks but substitutes for routine tasks whilst not affecting manual tasks.

Taken together, our findings have important implications for the debate about the role of government policies in encouraging productivity growth.9.$^{9}$ our estimates suggest that policy increasing the broadband penetration rates could enhance firm productivity. A related issue is why policy changes, even if they encourage productivity, do not always happen. One explanation is that established interests earning rents in the unreformed environment could be able to stave off reform. Examining who wins, who loses, and by how much could inform about the nature of these barriers and how to design compensation schemes. Our study points to the skill bias of broadband induced shift in production technology as a barrier to government investment in broadband infrastructure.

The paper unfolds as follows. Section 2 presents a framework for estimation of technological change in production and discusses previous research. Section 3 describes our data, before Section 4 discusses the expansion of broadband internet. Section 5 presents our empirical strategy. Section 6 describes our main findings, discusses their economic significance, and reports results from a number of robustness checks. Section 7 explores possible mechanisms. The final section offers some concluding remarks.

\footnotetext{
${ }^{8}$ See also Autor, Katz and Kearney (2006, 2008), Goos and Manning (2007), Black and Spitz-Oener (2010), Firpo, Fortin, and Lemieux (2011), Acemoglu and Autor (2011), Autor and Dorn (2013), and Michaels, Natraj, and Van Reenen (forthcoming). A related literature argues that ICT changes workplace organization and practices, by increasing skill requirements, worker autonomy and management's ability to monitor workers (see e.g. Caroli and Van Reenen, 2001; Bresnahan, Brynjolfsson, and Hitt, 2002. Brynjolfsson and Hitt, 2003, Bloom, Garicano, Sadun, and Van Reenen, 2009).

${ }^{9}$ Several studies have evaluated reforms with plausibly productivity enhancing effects (see the discussion in Syverson, 2011). One example is Olley and Pakes (1996), examining the impact of deregulation on productivity growth in the U.S. telecommunication industry. Another example is Pavcnik (2002), investigating the effects of liberalized trade on firm productivity in Chile.
} 


\section{Technological change in production}

\subsection{A framework for estimation}

Economic theory views the production technology as a function describing how a collection of factor inputs can be transformed into output, and it defines a technological change as a shift in the production function, i.e., a change in output for given inputs. Consider a Cobb-Douglas production technology with exponents that potentially change with the adoption of broadband internet:

$$
Y_{i t}=e^{\alpha_{0}+D_{i t} \alpha_{1}} K_{i t}^{\beta_{k 0}+D_{i t} \beta_{k 1}} U_{i t}^{\beta_{u 0}+D_{i t} \beta_{u 1}} S_{i t}^{\beta_{s 0}+D_{i t} \beta_{s 1}} e^{\varepsilon_{i t}},
$$

where $Y_{i t}$ represents output of firm $i$ in period $t, K_{i t}, U_{i t}$ and $S_{i t}$ are inputs of capital, unskilled, and skilled labor, respectively, $e^{\alpha_{0}+D_{i t} \alpha_{1}}$ is the average total factor productivity (TFP), and $e^{\varepsilon_{i t}}$ is the time- and firm-specific deviation from average TFP. Equation (1) extends on the usual Cobb-Douglas technology through the indicator variable $D_{i t}$, which is equal to one if firm $i$ has broadband internet in period $t$ (and zero otherwise). This simple extension allows for the possibility that broadband adoption is both factor-neutral $\left(\alpha_{1} \neq 0\right)$ and factor-biased $\left(\beta_{k 1} \neq 0, \beta_{u 1} \neq 0\right.$ or $\left.\beta_{s 1} \neq 0\right)$.

By estimating production functions like (1), we will explore several forms of factorbiased technological change that are discussed in the literature (see e.g. Berman, 2000). Broadband adoption is absolutely skill biased if the output elasticity of skilled workers increases,

$$
\beta_{s 1}>0
$$

while broadband adoption is relatively skill biased if

$$
\frac{\beta_{s 1}}{\beta_{s 0}}>\frac{\beta_{u 1}}{\beta_{u 0}}
$$

and broadband adoption is strongly skill biased if

$$
\beta_{s 1}>0>\beta_{u 1}
$$

A complementary approach to assess how broadband adoption shifts the production technology is to examine the labor market implications. Under standard conditions, relative skill bias implies that relative wages of skilled workers increase, holding the ratio of labor inputs fixed; or that the employment share of skilled workers increases, keeping relative wages constant. These two implications have been treated as alternative symptoms of skill-biased technological change in the literature. By comparison, strong skill bias implies that wages or employment rate of unskilled workers decreases with broadband adoption. By evaluating how the staged expansion of broadband internet affected hourly 
wages and employment rates in local labor markets, we will examine the implications of different forms of skill-biased technological change.

\subsection{Empirical challenges and previous research}

To estimate how broadband adoption shifts the production technology, it is useful to transform (1) to a linear production function:

$$
y_{i t}=\alpha_{0}+\beta_{k 0} k_{i t}+\beta_{u 0} u_{i t}+\beta_{s 0} s_{i t}+D_{i t}\left[\alpha_{1}+\beta_{k 1} k_{i t}+\beta_{s 1} s_{i t}+\beta_{u 1} u_{i t}\right]+\varepsilon_{i t},
$$

where lower-case letters refer to natural logarithms. While there exists a large literature on the identification and estimation of production functions ${ }^{10}$ there is little direct evidence on how adoption of new technology changes the productivity of different types of workers.

One reason is the difficulty in accessing data on technology adoption which can be linked with firm-level information on value added, capital, and labor by skill level. For instance, typical annual accounts data reports labor costs as average (or total) wages for all workers, rather than wages by the skill level of the workers (Van Beveren, 2012). Moreover, statistical agencies have only recently started to systematically collect ICT information at the firm level (Draca, Sadun, and Van Reenen, 2007). In most cases, this information relates to broad measures of expenditure or usage of ICT, rather than precise measures of specific technological changes.

Another reason is the threats to identification of production functions. A key concern is the likelihood that some determinants of production are unobserved to the econometrician but observed by the firm; if adoption of new technology depends on unobserved productivity, then OLS estimates of (2) will be biased. Several studies illustrate the difficulty in drawing credible inferences absent an appropriate instrumental variable. DiNardo and Pischke (1997) suggest that computer users possess unobserved skills which might have little to do with computers but which raise their productivity. Beaudry and Green $2003 ; 2005)$ and Beaudry, Doms, and Lewis (2010) show the speed and extent of computer adoption are likely endogenous and reflect principles of comparative advantage. Another generic concern in estimation of production functions is that the levels of capital and labor chosen could be correlated with unobserved factors of productivity. Olley and Pakes (1996) and Levinsohn and Petrin (2003) develop methods for estimating production functions that control for correlations between the use of factor inputs and unobserved productivity. However, most studies of technological change in production ignore these threats to identification and simply estimate a production function using OLS (Draca, Sadun, and Van Reenen, 2007). In particular, there have been few attempts to find instruments that affect the decision to adopt new technology.

Because we have data with firm-level information on value added, capital, labor by

\footnotetext{
${ }^{10}$ For recent reviews, see Draca, Sadun, and Van Reenen (2007) and Van Beveren (2012).
} 
skill level and broadband adoption, we are able to estimate production functions like (2); as a source of exogenous variation in broadband adoption, we exploit that the necessary infrastructure was established in different areas at different times; and following Levinsohn and Petrin (2003), we use intermediate inputs to proxy for unobserved productivity in the production function. This enables us to address the threats to identification and provide novel evidence on how broadband adoption in firms shifts the production technology and changes the productivity of different types of workers. The wage regressions which include interactions between skill levels and broadband internet allow us to examine the implications of skill-biased change without invoking the full set of assumptions behind the production function estimation.

\section{Data}

Our analysis uses several data sources, which we can link through unique identifiers for each firm, employee, and municipality. The coverage and reliability of Norwegian data are rated as exceptional in international quality assessments (see e.g. Atkinson, Rainwater, and Smeeding, 1995). Below we describe our data and sample selection, while details about the data sources and each of the variables are given in Appendix Table A1.

\section{Firm and worker data}

Our firm data comes from administrative registers, which are updated annually by Statistics Norway and verified by the Norwegian Tax Authority. The data comprises all non-financial joint-stock firms over the period 1999-2008.11 It contains detailed information from the firm's balance sheets on output (such as revenues) and inputs (such as capital, labor, intermediates) as well as 4-digit industry codes and geographical identifiers at the municipality level.

We merge the firm data set with a linked employer-employee registry that contains complete records of all firms and workers for the period 1999-2008. For every employee, we know his or her length and field of education, and annual labor income. In our baseline specification, we define an employee as skilled if he or she has completed high school, while employees with less schooling are defined as unskilled. In much of our analysis, we refine these often used proxies for skill levels: We divide skilled workers into medium skilled (high school graduates) and high skilled (post secondary education); and we interact post-secondary education with field of study.

\section{Internet data}

For the period 2001-2007, we have (i) data on broadband subscription for a stratified random sample of firms, and (ii) complete records of the fraction of households that have

\footnotetext{
${ }^{11}$ These firms cover the vast majority of revenues and workers in the private sector (about $81 \%$ of revenues and $71 \%$ of workers in 2001).
} 
access to broadband internet in every municipality. As explained in detail below, we will use the former to measure broadband adoption in firms, while the latter will form the basis for our instrumental variable. Throughout this paper, broadband is defined as internet connections with download speed that exceeds $256 \mathrm{kbit} / \mathrm{s}$.

Our data on broadband subscriptions of firms comes from the annual Community Survey on ICT Usage of Firms, performed by Statistics Norway. This survey includes information on the use of broadband internet in firms. In each year, the survey samples from the universe of joint-stock firms with at least five employees. The survey design is a stratified random sampling by industry and the number of employees.

The data on broadband access comes from the Norwegian Ministry of Government Administration. The ministry monitors the access of broadband internet to households, and the suppliers of broadband access to end-users are therefore required to file annual reports about their coverage rates to the Norwegian Telecommunications Authority. The coverage rates are based on information on the area signal range of the local access points and detailed information on the place of residence of households. In computing the coverage rates at the municipality level, it is taken into account that multiple suppliers may provide broadband access to households living in the same area, so that double counting is avoided.

\section{Socio-economic data}

Most of our socio-economic data come from administrative registers provided by Statistics Norway. Specifically, we use a rich longitudinal database which covers every resident from 1998 to 2008. It contains individual demographic information (regarding gender, age, marital status and number of children), socio-economic data (educational attainment, income, employment status), and geographic identifiers for municipality of residence. The information on educational attainment is based on annual reports from Norwegian educational establishments, whereas the income data and employment data are collected from tax records and other administrative registers. The household information is from the Central Population Register.

\section{Hourly wages and occupation}

While the employer-employee registry contains data on employment status and annual wages of all workers, it does not provide information on hourly wages (or hours of work). When looking at the impact of broadband internet on hourly wages, we use data from Statistics Norway's Wage Statistics Survey. In each year, the survey provides information on hourly wages and occuptions. For employees in the private sector, the data is based on an annual stratified random sampling of all firms. The survey covers all employees in the public sector. Taken together, the information on hourly wages covers about 80 percent of Norwegian employees in every year (100 percent of the public sector employees and 70 
percent of the private sector employees).

\section{Sample selection and summary statistics}

In the production function estimation, we use the sample of joint-stock firms recorded in the internet survey (which all have at least five employees). In the interest of external validity, we exclude firms that are carrying out extraction of natural resources (including oil, gas and fish) ${ }^{12}$ We refine this sample to be appropriate for estimation of production functions by focusing on firms with at least one employee in each of the two levels of skill. The baseline sample consists of 18,675 firms over the period 2001-2007. Throughout the paper, we use sampling weights to produce representative estimates for the corresponding population of joint-stock firms $(192,312$ firms $) 13$

Table 1 displays summary statistics for key firm variables over time. The first panel displays the mean of output and non-labor inputs over time, with standard deviations in parentheses. In the production function, we use value added as the dependent variable, defined as revenues (total sales) net of intermediates (procurement of materials and intermediate inputs). We measure capital as the value of total stock of fixed assets. It is evident that these variables are fairly stable over time, perhaps with a weakly increasing trend in revenues, value added and intermediates 14

The second and third panel of Table 1 show means and standard deviations of wage bills and number of employees by skill levels. There is a steady increase in both the wage bills and the number of employees over time, especially for the high skilled. Following Fox and Smeets (2011), our main analysis measures labor inputs by wage bills instead of the number of workers. This has the advantage of making the measure of physical capital and human capital more comparable: Physical capital is measured in terms of monetary units to reflect the quality of the machinery employed, while using the wage bill to proxy for labor input also implies measuring labor in terms of its expense in order to better reflect its quality. 15

Appendix Figure A1 displays the distribution of firms by industry. This figure shows the industry composition in our sample and in the corresponding population of firms. The four main industries are wholesale/retail, manufacturing, construction, and real estate/business services. This holds true both in terms of number of firms, aggregate value added, number of employees, and total wage bills. We can also see that the distributions in our sample (with sampling weights) closely mirror the distributions for the population

\footnotetext{
${ }^{12}$ The production function estimates barely move if we include firms carrying out extraction of natural resources.

${ }^{13}$ The production function estimates are very similar if we instead use the unweighted sample of firms. The same is true if we exclude firms which locate in the capital (Oslo) or the three big cities.

${ }^{14}$ Throughout this paper, all monetary figures are fixed at 1998 level after adjusting for inflation. For the figures expressed in U.S. dollars (USD), we have used the following exchange rate: NOK/USD = 7.5.

${ }^{15}$ Our findings of skill-biased technical change from broadband adoption in firms are robust to measuring labor inputs by the number of workers instead of the wage bill.
} 
Table 1. Descriptive statistics of baseline firm sample

\begin{tabular}{lccccc}
\hline & 2001 & 2004 & 2007 & Overall & Overall \\
\hline Input-output (USD, thousands) & $(\log )$ & $(\log )$ & $(\log )$ & $(\log )$ & $($ level $)$ \\
\hline Revenues & 7.45 & 7.45 & 7.72 & 7.51 & 6,190 \\
& $(1.20)$ & $(1.23)$ & $(1.35)$ & $(1.26)$ & $(45,766)$ \\
Value added & 6.65 & 6.68 & 6.99 & 6.74 & 2,412 \\
& $(1.10)$ & $(1.12)$ & $(1.24)$ & $(1.15)$ & $(14,894)$ \\
Intermediates & 6.45 & 6.42 & 6.60 & 6.47 & 3,779 \\
& $(1.82)$ & $(1.84)$ & $(2.01)$ & $(1.85)$ & $(36,864)$ \\
Capital & 4.54 & 4.34 & 4.50 & 4.41 & 1,112 \\
& $(1.77)$ & $(1.88)$ & $(2.01)$ & $(1.88)$ & $(18,532)$ \\
\hline Wage bills (USD, thousands) & $(\log )$ & $(\log )$ & $(\log )$ & $(\log )$ & $($ level) \\
\hline Total & 5.72 & 5.79 & 6.20 & 5.87 & 906 \\
& $(1.07)$ & $(1.10)$ & $(1.16)$ & $(1.12)$ & $(5,261)$ \\
Unskilled & 4.78 & 4.74 & 5.03 & 4.83 & 336 \\
& $(1.28)$ & $(1.30)$ & $(1.35)$ & $(1.29)$ & $(2,355)$ \\
Skilled & 4.92 & 5.08 & 5.57 & 5.17 & 570 \\
& $(1.37)$ & $(1.38)$ & $(1.41)$ & $(1.39)$ & $(3,287)$ \\
\hline Employees & $(\log )$ & $(\log )$ & $(\log )$ & $(\log )$ & $($ level) \\
\hline Total & 2.67 & 2.71 & 3.03 & 2.78 & 34 \\
& $(0.91)$ & $(0.91)$ & $(0.99)$ & $(0.93)$ & $(199)$ \\
Unskilled & 1.86 & 1.81 & 2.01 & 1.88 & 15 \\
& $(1.04)$ & $(1.05)$ & $(1.13)$ & $(1.06)$ & $(107)$ \\
Skilled & 1.88 & 2.01 & 2.40 & 2.07 & 19 \\
& $(1.07)$ & $(1.04)$ & $(1.14)$ & $(1.08)$ & $(100)$ \\
\hline Number of firms & & & & & \\
\hline Survey & 2,422 & 2,536 & 3,341 & & 18,675 \\
Population & 26,631 & 27,623 & 27,807 & 192,312 \\
\hline
\end{tabular}

Note: The baseline firm sample consists of joint-stock firms recorded in the internet survey. Sampling weights are used to ensure representative results for the population of joint-stock firms. (Un)Skilled comprises workers with(out) high school diploma. Detailed descriptions of the variables are given in Appendix Table A1 
of firms. The ability of our sampling weights to produce representative estimates are confirmed in Appendix Figures A2 and A3. The former displays the distributions of output and inputs across firms, while the latter shows the time trends in these variables.

Appendix Table A2 reports estimates from a standard Cobb-Douglas production function (without broadband adoption), based on our sample (with sampling weights) and the population of firms. The first two columns report OLS estimates, while the last two columns use the method for estimating production functions proposed by Levinsohn and Petrin (2003). It is evident that whether we use our sample or the population of firms matters little for the estimated output elasticities. We can also see that our estimates align well with the findings in previous studies. As predicted by theory, OLS overstates the labor coefficients because the level of inputs chosen is positively correlated with unobserved productivity. The magnitudes of the output elasticities of capital and labor are comparable

to what found in previous studies using micro data (see e.g. Pavcnik, 2002, Fox and Smeets, 2011).

Lastly, Appendix Table A3 displays summary statistics for the labor outcomes over time. When estimating the employment effects, we consider the full population of individuals between the ages of 18 and 67 (the mandatory retirement age). To estimate the impact on hourly wages, we consider all workers between the ages of 18 and 67 who are recorded in the wage statistics surveys. Due to a sluggish Norwegian economy, the employment rates decline somewhat between 2000 and 2004. By comparison, hourly wages were steadily increasing over over the entire period 2001-2007.

\section{Expansion of broadband internet}

Over the past decade, many OECD countries were planning the expansion of services related to information and communications technology. In Norway, the key policy change came with the National Broadband Policy, introduced by the Norwegian Parliament in the late 1990s. This section provides details about the program and describes the expansion of broadband internet 16

\section{The program}

The National Broadband Policy had two main goals. The first was to ensure that every area of the country had access to broadband at a reasonable and uniform price. The second was to ensure that the public sector quickly adopted broadband internet.

The Norwegian government took several steps to reach these goals. First and foremost, it invested heavily in the necessary infrastructure. The investment in infrastructure was largely channeled through the (state-owned) telecom company Telenor, which was the sole supplier of broadband access to end-users in the early 2000s and continues to be the main

\footnotetext{
${ }^{16}$ Our discussion draws on Bhuller, Havnes, Leuven, and Mogstad (forthcoming).
} 
supplier today. Moreover, virtually all broadband infrastructure was, and still is, owned and operated by Telenor.

Second, local governments were required to ensure access to broadband internet by 2005 to local public institutions, such as administrations, schools, and hospitals (St.meld.nr. 49, 2002-2003). To assist municipalities in rural areas, the federal government provided financial support through a funding program known as Høykom. Local governments could receive funds from this program by submitting a project plan that had to be evaluated by a program board with expert evaluations. The stated aim was to ensure broadband coverage throughout the country. Once approved, financial support was provided in the initial years of broadband access, thus making it possible for public institutions to cover relatively high initial costs 17

\section{Supply and demand factors}

The transmission of broadband signals through fiber-optic cables required installation of local access points. Since 2000, such access points were progressively rolled out, generating considerable spatial and temporal variation in broadband coverage. The staged expansion of access points was in part due to limited public funding, but also because Norway is a large and sparsely populated country. There are often long driving distances between the populated areas, which are mostly far apart or partitioned by mountains or the fjord-gashed shoreline 18

The government reports describing the National Broadband Policy and the roll-out of broadband access points (see St.meld.nr. 38 (1997-1998); St.meld.nr. 49 (2002-2003); Bhuller, Havnes, Leuven, and Mogstad, forthcoming), suggest that the main supply factors determining the timing of roll-out are topographical features and existing infrastructure (such as roads, tunnels, and railway routes), that slow down or speed up physical broadband expansion. 19 Based on the program accounts, we expect the potential demand factors to be related to public service provision, income level, educational attainment, and the degree of urbanization in the municipality.

\footnotetext{
${ }^{17}$ During the period 1999-2005, the Høykom program received more than 1000 such applications and co-funded nearly 400 projects, allocating a total of 50 million Euros (NOK 400 million). From 2002, the Ministry of Education and Research co-financed another scheme (Høykom skole), providing financial support for broadband infrastructure in public schools. There are virtually no private schools in Norway.

${ }^{18}$ The Norwegian territory covers about 149,400 square miles, an area about the size of California or Germany, with around $13 \%$ and $6 \%$ of those regions' populations (in 2008), respectively. The country is dominated by mountainous or high terrain, as well as a rugged coastline stretching about 1,650 miles, broken by numerous fjords and thousands of islands.

${ }^{19}$ The reason is that the transmission of broadband signals through fiber-optic cables required installation of local access points. In areas with challenging topography and landscapes, it was more difficult and expensive to install the local access points and the fiber-optic cables. Furthermore, the existing infrastructure mattered for the marginal costs of installing cables to extend the coverage of broadband within a municipality and to neighboring areas.
} 


\section{Descriptive statistics}

Figure 2 displays the evolution of broadband coverage to households between 2001 and 2007. In each year, we report the overall mean broadband coverage rate and the distribution of broadband coverage rates across municipalities. There is considerable variation, both across municipalities and over time. By 2000, broadband transmission centrals were installed in the cities of Oslo, Stavanger, and Trondheim, as well as in a few neighboring municipalities of Oslo and Trondheim. However, less than one-third of the households were covered by a broadband service provider in each of these municipalities.

Appendix Figure A4 shows geographic differences in the broadband coverage rates across municipalities over time. The maps illustrate that for a large number of municipalities there was no broadband coverage in the first few years, whereas most municipalities had achieved fairly high coverage rates in 2005. Moreover, there is considerable variation in coverage rates within the municipalities in these years.

Figure 2 displays the evolution of broadband internet use in firms between 2001 and 2007. There is considerable variation, both across municipalities and over time. In particular, the increase in coverage to households seems to have spilled over into increased access and take-up among firms. This is mirrored by an increase in the average usage rate of firms from around 20 percent in 2001 to above 80 percent by 2007 .

\section{$5 \quad$ Empirical strategy}

Randomizing broadband adoption is not feasible: We cannot in practice force firms to adopt a new technology. One can, however, think of a social experiment which randomizes broadband coverage at the municipality level. The randomization breaks the correlation between coverage rates and unobserved determinants of productivity. The intention of our IV-approach is to mimic this hypothetical experiment. Our source of exogenous variation in broadband adoption comes from the staged installation of broadband infrastructure, generating spatial and temporal variation in broadband coverage rates.

Below, we first describe how we use the roll-out of broadband coverage to address the endogeneity of internet adoption. Next, we discuss how we follow Levinsohn and Petrin (2003) in using intermediate inputs to control for correlation between input levels and the unobserved firm-specific productivity process.

\section{IV model}

Our IV strategy exploits that firms' access to and take-up of broadband internet changed as a side-effect of the expansion of broadband internet to households. This can be represented 
Figure 2. Broadband coverage rates of households and broadband subscription rates of firms
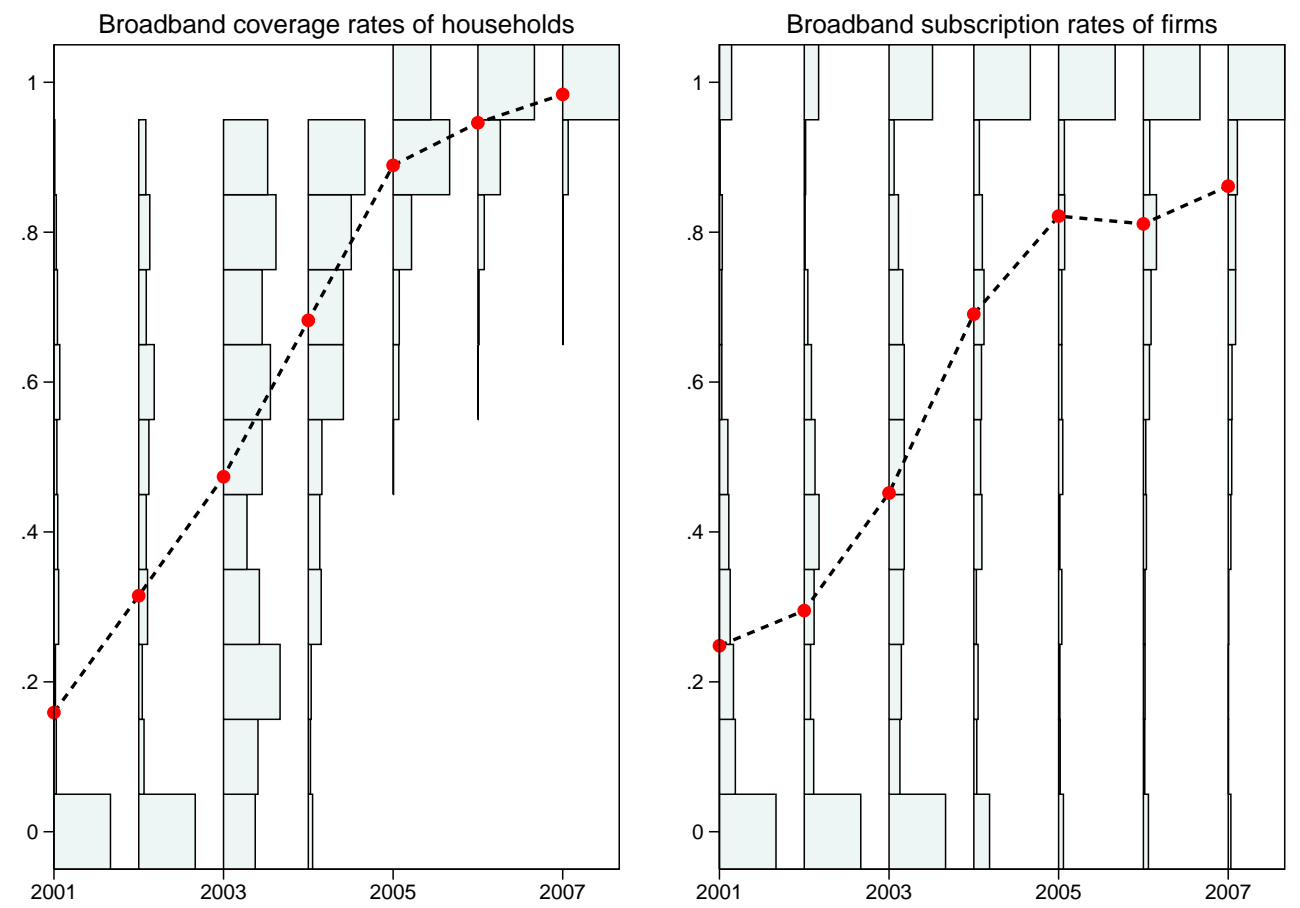

Note: The graphs show the overall mean and distribution of broadband coverage rates of households and broadband subscription rates of firms across municipalities for each year during the period 2001-2007. 
by the following system of equations, where the second stage is

$$
y_{i m k t}=x_{i m k t}^{\prime} \beta_{0}+D_{i m k t} x_{i m k t}^{\prime} \beta_{1}+\eta_{m}+\tau_{t}+\lambda_{k}+\varepsilon_{i m k t},
$$

while the first stages are given by

$$
\begin{aligned}
D_{i m k t} & =x_{i m k t}^{\prime} \delta+Z_{m t} x_{i m k t}^{\prime} \phi+\gamma_{m}+\theta_{t}+\sigma_{k}+\nu_{i m k t} \\
D_{i m k t} x_{1, i m k t} & =x_{i m k t}^{\prime} \delta_{1}+Z_{m t} x_{i m k t}^{\prime} \phi_{1}+\gamma_{1, m}+\theta_{1, t}+\sigma_{1, k}+\nu_{1, i m k t} \\
\vdots & =\vdots \\
D_{i m k t} x_{n, i m k t} & =x_{i m k t}^{\prime} \delta_{n}+Z_{m t} x_{i m k t}^{\prime} \phi_{n}+\gamma_{n, m}+\theta_{n, t}+\sigma_{n, k}+\nu_{n, i m k t}
\end{aligned}
$$

where $y$ is $(\log )$ value-added, $D$ is a dummy variable for whether the firm uses broadband internet, $Z$ is the fraction of households in a municipality with access to broadband internet, and $x$ is a vector of $n$ inputs (in $\log$ ) and a constant term. In all cases, subscript $i$ denotes firm, subscript $k$ denotes industry, subscript $m$ denotes municipality and subscript $t$ denotes year. All equations include a full set of municipality indicators $\left(\eta_{m}, \gamma_{m}\right)$, year indicators $\left(\tau_{t}, \theta_{t}\right)$, and (4-digit) industry indicators $\left(\sigma_{k}, \lambda_{k}\right)$. Throughout the paper, the standard errors are clustered at the municipality level and robust to heteroskedasticity.

Unobservable determinants of production that are fixed at the municipality or industry level will be controlled for through the municipality and industry indicators, just like common time shocks are absorbed by the year indicators. To check that the estimated output elasticities are not confounded by time-varying observable factors, we report results with and without a large set of time-varying controls. In particular, we show that our estimates change little if we add control variables for the potential supply and demand factors discussed above.

\section{Assessing the IV model}

Our IV model - which controls for municipality (time and industry) fixed effects - is motivated by two features of the program. First, most of the supply and demand factors tend to vary little over time. Second, the timing of the roll-out is unlikely to co-vary with key correlates of production.

To investigate whether the data is consistent with these program features, we first regress $Z_{m t}$ on municipality, time and industry fixed effects as well as time-varying supply and demand factors. We find that $89 \%$ of the variation in broadband coverage can be attributed to time-invariant municipality and industry characteristics and common time effects, while less than $1 \%$ of the variation in broadband coverage can be attributed to a large set of time-varying variables ${ }^{20}$

\footnotetext{
${ }^{20}$ The time-varying variables include demographic factors (income level, education, share of population residing in a densely populated locality, size of population, and level of unemployment), inputs and output
} 
Second, we examine the relationship between the timing of broadband roll-out and baseline municipality characteristics. To this end, we estimate the following equation

$$
\Delta Z_{m t}=\eta_{m}+\left[\theta_{t} \times W_{m, 2000}\right]^{\prime} \psi_{t}+\epsilon_{m t}
$$

where $\Delta Z_{m t}=Z_{m t}-Z_{m, t-1}$ and $W_{m, 2000}$ includes municipality-level information from year 2000 on demography, average levels of inputs and output, industry structures and skill composition. Demography includes income level, education, share of population residing in a densely populated locality (an urbanization indictor), size of population and level of unemployment. For inputs and output we have included municipality averages of revenues, intermediates, capital stock, number of workers and wage bill. As measures of industry structure, we use number of firms, employment share in manufacturing, employment share in wholesale, and employment share in services. The last group of municipality characteristics is the skill composition, measured as the shares of wages and workers by skill level.

Appendix Figure A5 plots the estimated coefficients from the vector $\psi_{t}$ for every $t$ (and the associated $95 \%$ confidence intervals). Our results indicate that broadband expansion is positively related to urbanization until 2002. From 2003 onwards, there appears to be no systematic relationship between the timing of the broadband expansion and this variable. But more importantly, the timing of the expansion does not correlate with baseline industry structure, the levels of output and inputs, as well as the skill composition. Nevertheless, in the robustness analysis we demonstrate that our estimates change little when allowing for different underlying time trends in firm productivity or labor outcomes across municipalities.

\section{Extension of the IV model}

The IV approach breaks the correlation between $D_{i m k t}$ and $\varepsilon_{i m k t}$. However, it is still possible that the factor inputs $x_{i m k t}$ are correlated with broadband adoption and unobserved productivity, which could bias the IV estimates of equation (3). Following Levinsohn and Petrin (2003, hereafter LP), we take a more structural approach to address this threat to identification of the production function. ${ }^{21}$

LP use a structural model of an optimizing firm to derive the conditions under which intermediate inputs can be used to proxy for unobserved productivity in the production

(municipality averages of revenues, intermediates, capital stock, number of workers and wage bill), industry structure (number of firms, employment share in manufacturing, employment share in wholesale, and employment share in services) and skill composition (shares of wages and workers by skill level).

${ }^{21}$ Levinsohn and Petrin (2003) extend on Olley and Pakes (1996) by using intermediate inputs instead of investments as a proxy for unobserved productivity. This addresses the problem that investment is zero in a non-trivial number of cases. Both studies also show how to address endogenous exit and entry of firms. Because our information on broadband adoption comes from repeated cross-sections (rather than panel data), we abstract from endogenous entry and exit. 
function. The error term $\varepsilon_{i m k t}$ is assumed to be additively separable in a transmitted component $\left(\omega_{i m k t}\right)$ and an i.i.d. component $\left(\chi_{i m k t}\right)$. The key difference between $\omega_{i m k t}$ and $\chi_{i m k t}$ is that the former is a state variable, and therefore impacts the firm's decision rule, while the latter has no impact on the firm's decision. The intermediate input demand function depends on the firm-specific state variables, $\omega_{i m k t}$ and $k_{i m k t}$,

$$
a_{i m k t}=g_{t}\left(\omega_{i m k t}, k_{i m k t}\right)
$$

and it must be monotonic in $\omega$ for all relevant $k 2^{22}$ The monotonicity condition for intermediate inputs means that conditional on capital, profit maximizing behavior must lead more productive firms to use more intermediate inputs.

The monotonicity allows $g_{t}\left(\omega_{i m k t}, k_{i m k t}\right)$ to be inverted to yield $\omega$ as a function of intermediate inputs and capital, $\omega_{i m k t}=\omega_{t}\left(a_{i m k t}, k_{i m k t}\right)$. By expressing the unobserved productivity variable $\omega_{i m k t}$ as a function of observables, we are able to control for $\omega_{i m k t}$ in the second stage equation:

$$
y_{i m k t}=x_{i m k t}^{\prime} \beta_{0}+D_{i m k t} x_{i m k t}^{\prime} \beta_{1}+\eta_{m}+\tau_{t}+\lambda_{k}+\omega_{t}\left(a_{i m k t}, k_{i m k t}\right)+\chi_{i m k t} .
$$

As in Olley and Pakes (1996) and LP, we use a polynomial expansion in $a$ and $k$ to approximate $\omega_{t}(\cdot)$. By simultaneous estimation of the first stage equations in (4) and the second stage equation in (7), we obtain consistent estimates of $\beta_{u 0}, \beta_{s 0}, \beta_{k 1}, \beta_{u 1}, \beta_{s 1}$, and $\Phi_{t}\left(a_{i m k t}, k_{i m k t}\right)=\beta_{k 0} k_{i m k t}+\omega_{t}\left(a_{i m k t}, k_{i m k t}\right)$.

While these output elasticities are sufficient to assess how broadband adoption affects labor productivity, we need to identify $\beta_{k 0}$ to recover the full shift in production technology. Because $k_{i m k t}$ is collinear with the non-parametric function $\omega_{t}\left(a_{i m k t}, k_{i m k t}\right)$, further assumptions are necessary. ${ }^{23}$ Details on how $\beta_{k 0}$ is estimated are found in Appendix B.

\section{Empirical results}

\subsection{Evidence on skill bias}

A virtue of our research design is that it provides a transparent way of showing how the skill bias of broadband internet is identified. To this end, we begin with a graphical depiction before turning to a more detailed regression-based analysis

\footnotetext{
${ }^{22}$ For simplicity, we assume as Olley and Pakes (1996) and Levinsohn and Petrin (2003) that capital is the only state variable over which the firm has control, while intermediates, labor and broadband internet are viewed as non-dynamic input factors.

${ }^{23} \beta_{k 1}$ is identified as the interaction of capital with $D_{i m k t}$ provides independent variation. Note also that the intercept in the production function is not separately identified from the mean of $E\left[\omega_{i m k t} \mid \omega_{i m k t-1}\right]$ without some further restriction.
} 
Figure 3. Association between broadband subscription and coverage rates, after taking out municipality, industry and year fixed effects

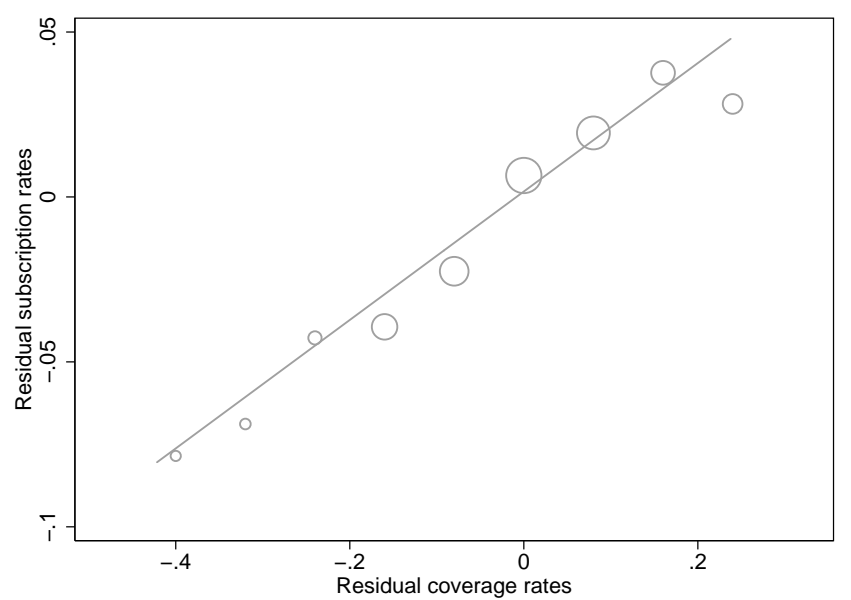

Note: Baseline firm sample over the period 2001-2007, consisting of joint-stock firms recorded in the internet survey. Bins are based on the residual subscription rates of firms with bin size $=0.08$. The size of the circle represents the number of firms in each bin. Sampling weights are used to ensure representative results for the population of joint-stock firms. The Y-axis reports residuals from a regression of broadband subscription rates of firms on municipality, industry and year fixed effects. The $\mathrm{X}$-axis reports residuals from a regression of broadband coverage rates of households on municipality, industry and year fixed effects.

\section{Graphical evidence}

Figure 3 illustrates the variation used in the first stages by drawing a scatter plot of the broadband coverage rates of households against the broadband user rates of firms. We let the size of the circle represent the number of firms in each bin. The figure shows a strong association between the coverage and user rates. This suggests a strong impact on broadband adoption of the increase in broadband coverage from the previous year. Indeed, when regressing user rates of firms on coverage rates of household as well as municipality, industry and year fixed effects, the coefficient on the coverage rate is about 0.23 with a standard error of 0.04 . It implies that a 10 percentage point increase in broadband coverage to households induces (an additional) $2.3 \%$ of the firms to adopt broadband internet.

Figure 1 in the introduction provided a visual representation of the reduced form of the IV model. In the same way, Appendix Figure A6 illustrates the reduced form of the LP approach by showing how LP estimates of the period-specific output elasticities vary with the roll-out of broadband coverage. Both set of estimates are summarized in Figure 4, where we normalize the period-specific output elasticities so that they equal one at time -1 . We can clearly see that the growth in broadband coverage is associated with an increase in the output elasticity of skilled labor, while the output elasticity of unskilled labor decreases. The similarity between the estimated output elasticities across the two graphs suggest that correlation between input levels and unobserved productivity 
is unlikely to drive our results. It is still possible that the association between broadband coverage and labor productivity is confounded by time-varying factors. However, there is no evidence of changes in a wide range of municipality level characteristics from time -1 to time zero, including industry structure, firm characteristics, skill composition and demographic characteristics ${ }^{24}$ As a result, the estimated output-elasticities barely move when we add time-varying control variables to the regression models.

\section{Regression results}

Table 2 reports production function estimates based on OLS, IV and LP. In all cases, we find that broadband adoption in firms favors skilled labor by increasing its relative productivity. Indeed, the output elasticity of skilled labor increases substantially, while broadband internet seems to be a substitute for unskilled labor. By comparison, there is little if any change in the output elasticity of capital. The full set of first stage results are reported in Appendix Table A4. The first stages are strong, with large F-statistics on the excluded instruments which mean weak instrument bias is not a concern.

To interpret the magnitude of these changes in output elasticities, it is useful to compute the implied marginal productivities. When using the LP estimates to compute marginal productivities, we find that for every $\$ 1$ spent on skilled labor, the production increases by $\$ 1.34$ in the absence of broadband internet. Broadband adoption in firms increases the productivity of skilled labor by $\$ 0.27$. For unskilled labor, however, this technological change lowers the marginal productivity by $\$ .06$; one explanation for this finding is that broadband in firms replaces tasks previously performed by unskilled labor; these workers may then be reallocated to tasks for which they have lower comparative advantage, which pushes their marginal productivity down.

The statistical tests reported in the lower panel of Table 2 suggest that broadband internet is strongly skill-biased. ${ }^{25}$ Under standard conditions, strong skill bias implies that wages or employment rates of (un)skilled workers should decrease (increase) with broadband internet. Table 3 examines these implications by estimating how the expansion of broadband internet affected hourly wages and employment rates in local labor market. Specifically, we run the following wage regression which includes interactions between broadband internet and individuals' skill level:

$$
y_{l m k t}=\beta_{U} U_{l m k t}+\beta_{S} S_{l m k t}+Z_{m t}\left(\gamma_{U} U_{l m k t}+\gamma_{S} S_{l m k t}\right)+X_{l m k t}^{\prime} \delta+\tau_{t}+\eta_{m}+\lambda_{k}+\varepsilon_{l m t}
$$

where $y_{l m k t}$ denotes $(\log )$ hourly wage or employment status of individual $l$ in municipality $m$ and industry $k$ in period $t$, and $X$ is a vector of controls for his or her gender and

\footnotetext{
${ }^{24}$ For brevity, we do not include these graphs, but they are available from the authors upon request.

${ }^{25}$ To test for strong skill bias, we use the method of Holm (1979) to take into account the multiplicity in testing $\beta_{s 1} \leq 0$ vs. $\beta_{s 1}>0$ and $\beta_{u 1} \geq 0$ vs. $\beta_{u 1}<0$.
} 
Figure 4. Normalized output elasticities, pre and post expansion

(a) Reduced form of IV

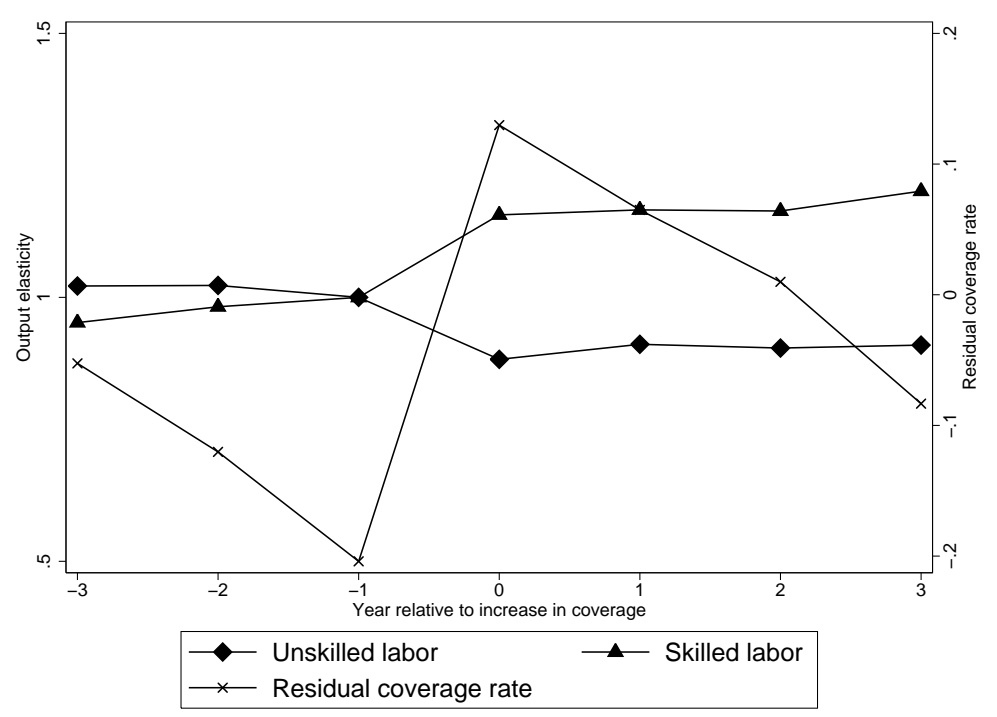

(b) Reduced form of LP

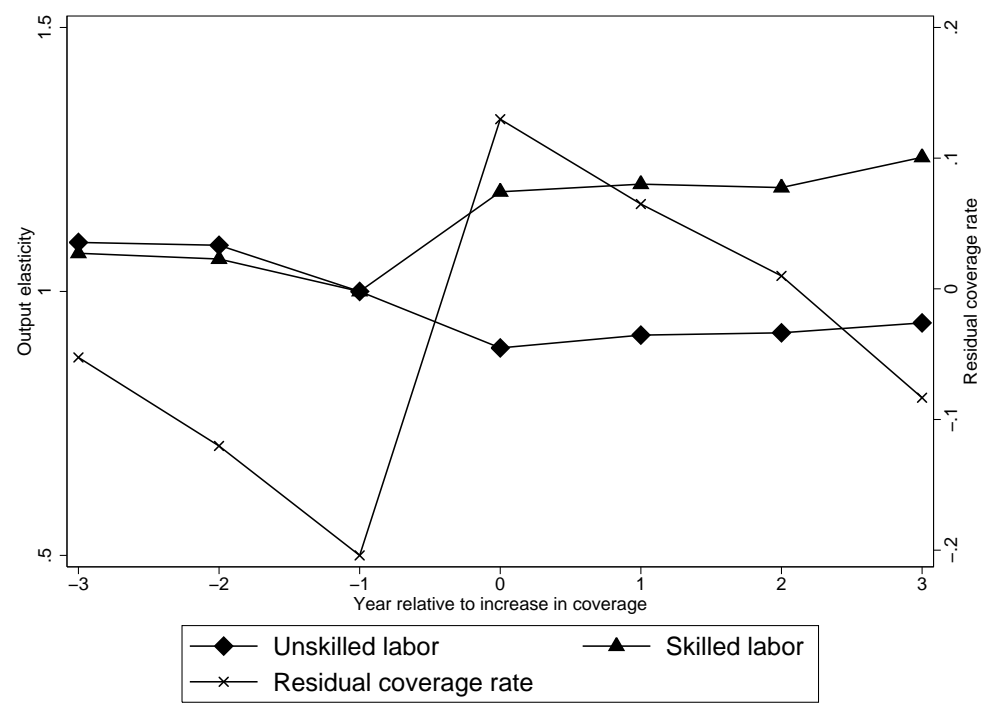

Note: Baseline firm sample over the period 2001-2007, consisting of joint-stock firms recorded in the internet survey. Sampling weights are used to ensure representative results for the population of joint-stock firms. Coverage rates are residuals from a regression of municipality-level broadband coverage on municipality, industry and year fixed effects. Time zero represents the year with the strongest growth in residual coverage rates in a given municipality. In each time period, we estimate production functions and wage regressions while controlling for municipality, industry and year fixed effects. Graph (a) reports period-specific OLS estimates of the output elasticity of skilled and unskilled labor. Graph (b) reports period-specific LP estimates of the output elasticity of skilled and unskilled labor. In each graph, the output elasticities are normalized so that they equal one at $t=-1$. 
Table 2. Production function estimates with two levels of skill

\begin{tabular}{|c|c|c|c|}
\hline & \multicolumn{3}{|c|}{ Output elasticities } \\
\hline & OLS & IV & LP \\
\hline \multirow[t]{2}{*}{ Capital } & $0.108^{* * *}$ & $0.113^{* * *}$ & $0.232^{* * *}$ \\
\hline & $(0.0069)$ & $(0.0170)$ & $(0.032)$ \\
\hline \multirow[t]{2}{*}{ Unskilled } & $0.302^{* * *}$ & $0.322^{* * *}$ & $0.256^{* * *}$ \\
\hline & $(0.0131)$ & $(0.0248)$ & $(0.0214)$ \\
\hline \multirow[t]{2}{*}{ Skilled } & $0.335^{* * *}$ & $0.310^{* * *}$ & $0.231^{* * *}$ \\
\hline & $(0.0155)$ & $(0.0253)$ & $(0.0196)$ \\
\hline \multirow[t]{2}{*}{ Internet $\times$ Capital } & -0.0016 & -0.0074 & -0.0070 \\
\hline & $(0.0086)$ & $(0.0248)$ & $(0.0202)$ \\
\hline \multirow[t]{2}{*}{ Internet $\times$ Unskilled } & -0.0198 & -0.0553 & $-0.0574^{*}$ \\
\hline & $(0.0145)$ & $(0.0396)$ & $(0.0333)$ \\
\hline \multirow[t]{2}{*}{ Internet $\times$ Skilled } & $0.136^{* * *}$ & $0.202^{* * *}$ & $0.141^{* * *}$ \\
\hline & $(0.0143)$ & $(0.0433)$ & $(0.0373)$ \\
\hline Null hypothesis & \multicolumn{3}{|c|}{ P-values } \\
\hline No absolute skill bias: $\beta_{s 1} \leq 0$ & 0.000 & 0.000 & 0.000 \\
\hline No relative skill bias: $\frac{\beta_{s 1}}{\beta_{s 0}} \leq \frac{\beta_{u 1}}{\beta_{u 0}}$ & 0.000 & 0.001 & 0.001 \\
\hline No strong skill bias: $\beta_{s 1} \leq 0, \beta_{u 1} \geq 0$ & 0.087 & 0.081 & 0.042 \\
\hline
\end{tabular}

Note: Baseline firm sample over the period 2001-2007, consisting of 18,675 joint-stock firms recorded in the internet survey. Sampling weights are used to ensure representative results for the population of joint-stock firms. (Un)Skilled comprises workers with(out) high school diploma. The standard errors are clustered at the municipality level and robust to heteroskedasticity. All regressions include fixed effect for year, municipality and industry. To test for strong skill bias, we use the method of Holm (1979). 
Table 3. Wage regressions with two levels of skill

\begin{tabular}{lcc}
\hline & $\begin{array}{c}\text { Log hourly wage } \\
(1)\end{array}$ & $\begin{array}{c}\text { Employment rate } \\
(2)\end{array}$ \\
\hline Unskilled & $9.700^{* * *}$ & $0.489^{* * *}$ \\
& $(0.0184)$ & $(0.0207)$ \\
Skilled & $9.847^{* * *}$ & $0.562^{* * *}$ \\
& $(0.0185)$ & $(0.0210)$ \\
Coverage $\times$ Unskilled & $-0.0281^{* * *}$ & $-0.0101^{* * *}$ \\
Coverage $\times$ Skilled & $(0.00356)$ & $(0.00262)$ \\
& $0.0143^{*}$ & $0.0144^{* * *}$ \\
& $(0.00837)$ & $(0.00491)$ \\
Null hypothesis & & \\
\hline No absolute skill bias: $\gamma_{S} \leq 0$ & & 0.002 \\
No relative skill bias: $\frac{\gamma_{S}}{\beta_{S}} \leq \frac{\gamma_{u}}{\beta_{u}}$ & 0.044 & 0.000 \\
No strong skill bias: $\gamma_{S} \leq 0, \gamma_{U} \geq 0$ & 0.000 & 0.002 \\
\hline
\end{tabular}

Note: Baseline samples for labor outcomes over the period 2001-2007, consisting of all workers aged 18-67 who are recorded in the wage statistics survey (Column 1; 8,759,386 observations) and the full population of individuals between the ages of 18 and 67 (Column 2; 20,327,515 observations). Both regressions include fixed effects for year, municipality and industry and controls for gender, years of experience and years of experience squared. (Un)Skilled comprises workers with(out) high school diploma. The standard errors are clustered at the municipality level and robust to heteroskedasticity. To test for strong skill bias, we use the method of Holm (1979).

potential experience (linear and squared terms). When estimating the employment effects, we consider the full population of individuals between the ages of 18 and 67 . The impact on hourly wages pertain to workers aged 18-67 who are recorded in the wage statistics surveys.

In line with the estimated changes in labor productivity, the wage regressions show that the expansion of broadband internet improves (worsens) the labor outcomes of (un)skilled workers. For instance, the estimates imply that a 10 percentage point increase in broadband coverage in a municipality raises wages of skilled workers in that local labor market by 0.14 percent. The statistical tests reported in the lower panel of Table 3 support the conclusion that broadband internet is strongly skill biased.

\subsection{Specification checks}

Table 2 demonstrated that the evidence on skill-biased technical change is robust to whether we use intermediate inputs to control for correlation between input levels and the unobserved firm-specific productivity process. We now report results from additional specification checks to further increase the confidence in our findings.

In Table 4, we challenge the validity of the empirical strategy in several ways. Column 1 repeats the baseline estimates, while columns 2-3 include a wide range of controls for 
time-varying demographic and industry characteristics. When we include these covariates, we find that the estimated output elasticities are quite similar to our baseline estimates.

An important requirement for our instrument to be valid is that the expansion of broadband internet is unrelated to different underlying time trends in firm productivity across municipalities. Columns 4-6 of Table 4 addresses this threat to identification. We first interact baseline (year 2000) covariates with a linear (column 4) and quadratic time trend (column 5). By including these controls in both the first and second stages, we allow the expansion of broadband internet to be related to different underlying time trends in productivity across municipalities, depending on their initial characteristics. A concern with these robustness checks is that baseline characteristics may not adequately capture differential time trends across municipalities. Column 6 includes linear municipality-specific time trends in both the first and second stages. It is reassuring to find that neither the IV estimates nor the LP estimates change significantly when allowing for differential time trends across municipalities.

In Table 5, we perform the same specification checks for the wage regressions. Consistent with the baseline estimates, the alternative specifications suggest that the expansion of broadband internet improves (worsens) the labor outcomes of skilled (unskilled) workers. 
Table 4. Specification checks for production function

\begin{tabular}{|c|c|c|c|c|c|c|c|}
\hline & & \multirow{3}{*}{$\begin{array}{c}\text { Baseline } \\
\text { (1) }\end{array}$} & & & \multicolumn{2}{|c|}{$\begin{array}{l}\text { Time interacted } \\
\text { with covariates }\end{array}$} & \multirow{3}{*}{$\begin{array}{c}\text { Linear } \\
\text { municipality trends } \\
(6)\end{array}$} \\
\hline & & & \multicolumn{2}{|c|}{ Covariates } & Linear & Quadratic & \\
\hline & & & (2) & $(3)$ & (4) & $(5)$ & \\
\hline \multirow{6}{*}{$\begin{array}{l}\text { Panel A: } \\
\text { IV }\end{array}$} & Internet $\times$ Capital & -0.00741 & -0.0104 & -0.0132 & -0.0183 & -0.0187 & -0.00101 \\
\hline & & $(0.0248)$ & $(0.0253)$ & $(0.0248)$ & $(0.0275)$ & $(0.0265)$ & $(0.0236)$ \\
\hline & Internet $\times$ Unskilled & -0.0553 & -0.0600 & -0.0598 & -0.0677 & -0.0664 & -0.0305 \\
\hline & & $(0.0396)$ & $(0.0406)$ & $(0.0403)$ & $(0.0422)$ & $(0.0420)$ & $(0.0431)$ \\
\hline & Internet $\times$ Skilled & $0.202^{* * *}$ & $0.202^{* * *}$ & $0.192^{* * *}$ & $0.195^{* * *}$ & $0.190^{* * *}$ & $0.163^{* * *}$ \\
\hline & & $(0.0433)$ & $(0.0441)$ & $(0.0438)$ & $(0.0451)$ & $(0.0445)$ & $(0.0410)$ \\
\hline \multirow{6}{*}{$\begin{array}{l}\text { Panel B: } \\
\text { LP }\end{array}$} & Internet $\times$ Capital & -0.00701 & -0.00950 & -0.0113 & -0.0188 & -0.0184 & -0.00247 \\
\hline & & $(0.0202)$ & $(0.0205)$ & $(0.0199)$ & $(0.0216)$ & $(0.0209)$ & $(0.0202)$ \\
\hline & Internet $\times$ Unskilled & $-0.0574^{*}$ & $-0.0608^{*}$ & $-0.0624^{*}$ & $-0.0707^{* *}$ & $-0.0692^{* *}$ & -0.0412 \\
\hline & & $(0.0333)$ & $(0.0340)$ & $(0.0339)$ & $(0.0352)$ & $(0.0348)$ & $(0.0334)$ \\
\hline & Internet $\times$ Skilled & $0.141^{* * *}$ & $0.140 * * *$ & $0.132^{* * *}$ & $0.134^{* * *}$ & $0.129^{* * *}$ & $0.105^{* * *}$ \\
\hline & & $(0.0373)$ & $(0.0377)$ & $(0.0370)$ & $(0.0375)$ & $(0.0373)$ & $(0.0369)$ \\
\hline \multirow[t]{2}{*}{ Controls } & Demographic & & \multirow[t]{2}{*}{$\sqrt{ }$} & $\sqrt{ }$ & $\sqrt{ }$ & $\sqrt{ }$ & $\sqrt{ }$ \\
\hline & Industry & & & $\sqrt{ }$ & $\sqrt{ }$ & $\sqrt{ }$ & $\sqrt{ }$ \\
\hline
\end{tabular}

Note: Baseline firm sample over the period 2001-2007, consisting of 18,675 joint-stock firms recorded in the internet survey. Sampling weights are used to ensure representative results for the population of joint-stock firms. (Un)Skilled comprises workers with(out) high school diploma. The standard errors are clustered at the municipality level and robust to heteroskedasticity. All regressions include fixed effect for year, municipality and industry. Column (2) adds demographic controls to the baseline model, including municipality-level information on average household income, mean years of schooling, share of population residing in a densely populated locality, size of population and level of unemployment. Column (3) also includes industry controls, consisting of municipality averages of revenues, intermediates, capital stock, number of workers and wage bills as well as employment share in manufacturing, employment share in wholesale, employment share in services, and shares of wages and workers by skill level. Columns (4) and (5) interact linear and quadratic time trends with baseline values (year 2000) of these covariates. Column (6) includes municipality-specific linear time trends. 
Table 5. Specification checks for wage regression

\begin{tabular}{|c|c|c|c|c|c|c|c|}
\hline & & \multirow{3}{*}{$\begin{array}{c}\text { Baseline } \\
\text { (1) }\end{array}$} & & & \multicolumn{2}{|c|}{$\begin{array}{l}\text { Time interacted } \\
\text { with covariates }\end{array}$} & \multirow{3}{*}{$\begin{array}{c}\text { Linear } \\
\text { muncipality trends }\end{array}$} \\
\hline & & & \multicolumn{2}{|c|}{ Covariates } & Linear & Quadratic & \\
\hline & & & $(2)$ & (3) & (4) & $(5)$ & \\
\hline \multirow{4}{*}{$\begin{array}{l}\text { Panel A: } \\
\text { Employment rate }\end{array}$} & Cov $\times$ Unskilled & $-0.0101^{* * *}$ & $-0.00885^{* * *}$ & $-0.00893^{* * *}$ & $-0.0141^{* * *}$ & $-0.0147^{* * *}$ & $-0.0128^{* * *}$ \\
\hline & & $(0.00262)$ & $(0.00221)$ & $(0.00235)$ & $(0.00330)$ & $(0.00346)$ & $(0.00338)$ \\
\hline & Cov $\times$ Skilled & $0.0144^{* * *}$ & $0.0155^{* * *}$ & $0.0154^{* * *}$ & $0.0103^{* * *}$ & $0.00974^{* * *}$ & $0.0116^{* * *}$ \\
\hline & & $(0.00491)$ & $(0.00373)$ & $(0.00359)$ & $(0.00262)$ & $(0.00252)$ & $(0.00260)$ \\
\hline \multirow{6}{*}{$\begin{array}{l}\text { Panel B: } \\
\text { Log hourly wage }\end{array}$} & Cov $\times$ Unskilled & $-0.0281^{* * *}$ & $-0.0270^{* * *}$ & $-0.0271^{* * *}$ & $-0.0282^{* * *}$ & $-0.0283^{* * *}$ & $-0.0310^{* * *}$ \\
\hline & & $(0.00356)$ & $(0.00392)$ & $(0.00410)$ & $(0.00634)$ & $(0.00636)$ & $(0.00620)$ \\
\hline & Cov $\times$ Skilled & $0.0143^{*}$ & $0.0152^{*}$ & $0.0152^{* *}$ & $0.0134^{* * *}$ & $0.0133^{* * *}$ & $0.0106^{* *}$ \\
\hline & & $(0.00837)$ & $(0.00786)$ & $(0.00756)$ & $(0.00498)$ & $(0.00504)$ & $(0.00535)$ \\
\hline & Demographic & & $\sqrt{ }$ & $\sqrt{ }$ & $\sqrt{ }$ & $\sqrt{ }$ & $\sqrt{ }$ \\
\hline & Industry & & & $\sqrt{ }$ & $\sqrt{ }$ & $\sqrt{ }$ & $\sqrt{ }$ \\
\hline
\end{tabular}

Note: Baseline samples of labor outcomes over the period 2001-2007, consisting of all workers aged 18-67 who are recorded in the wage statistics survey (Panel B; 8,759,386 observations) and the full population of individuals between the ages of 18 and 67 (Panel A; 20,327,515 observations). All regressions include fixed effects for year, municipality and industry, and controls for gender, years of experience and years of experience squared. (Un)Skilled comprises workers with(out) high school diploma. The standard errors are clustered at the municipality level and robust to heteroskedasticity. Column (2) adds demographic controls to the baseline model, including municipality-level information on average household income, mean years of schooling, share of population residing in a densely populated locality, size of population and level of unemployment. Column (3) also includes industry controls, consisting of municipality averages of revenues, intermediates, capital stock, number of workers and wage bills as well as employment share in manufacturing, employment share in wholesale, employment share in services, and shares of wages and workers by skill level. Columns (4) and (5) interact linear and quadratic time trends with baseline values (year 2000) of these covariates. Column (6) includes municipality-specific linear time trends. 


\subsection{Understanding the pattern of adoption}

Following Imbens and Angrist (1994), our IV and LP estimates should be interpreted as the local average treatment effects (LATE) for the sub-population of firms that quickly adopt broadband when it becomes accessible (ofted called "compliers"). To characterize these compliers and understand the pattern of broadband adoption, we estimate the following regression model separately for different types of firms:

$$
D_{i m k t}=\delta Z_{m t}+\gamma_{m}+\theta_{t}+\sigma_{k}+\nu_{i m k t}
$$

We partition the baseline sample into ten mutually exclusive groups by industry and share of workers with high school diploma (above and below median within each industry). Column 1 of Table 6 displays the proportion of the sample in each industry-skill group. The estimates of $\delta$ for the different types of firms are shown in the second column of Table 6. The proportion of the compliers of a given type is then calculated as the ratio of $\hat{\delta}$ for that subgroup to the $\hat{\delta}$ in the overall sample, multiplied by the proportion of the sample in the industry-skill group. Column 3 shows the distribution of the compliers by industry and skill intensity. We see that firms with a large share of high skilled workers are overrepresented among the compliers in every industry compared to the sample of firms at large.

Columns 4-6 of Table 6 report the characteristics of each industry-skill group prior to the roll-out (in year 2000). Column 4 shows that in every industry the complier firms tend to be relatively large or productive (as measured by value added), while columns 5 and 6 show that they are more likely to deploy high skilled labor and use computers intensively. These findings suggest that when broadband internet becomes available, it is not randomly adopted; instead, it is more quickly adopted in firms in which complementary factors are abundent, including computers and skilled workers. This conforms to the predictions of a model of endogenous technology adoption where firms' choices reflect principles of comparative advantage (see e.g. Beaudry and Green, 2003, 2005; Beaudry, Doms, and Lewis, 2010). The pattern of broadband adoption illustrates that the estimated effects pertain to a selective subgroup of early adopters of broadband internet; as a result, we need to be cautious in extrapolating these local estimates to the longer-run impact of broadband adoption for the population of firms at large. ${ }^{26}$

\footnotetext{
${ }^{26}$ For the same reason, we also need to be cautious in comparing the OLS estimates to the IV or LP estimates. The OLS estimates differ either because of endogeneity bias or because of heterogeneity across firms in the impact of adopting broadband internet.
} 
Table 6. Characterizing complier firms

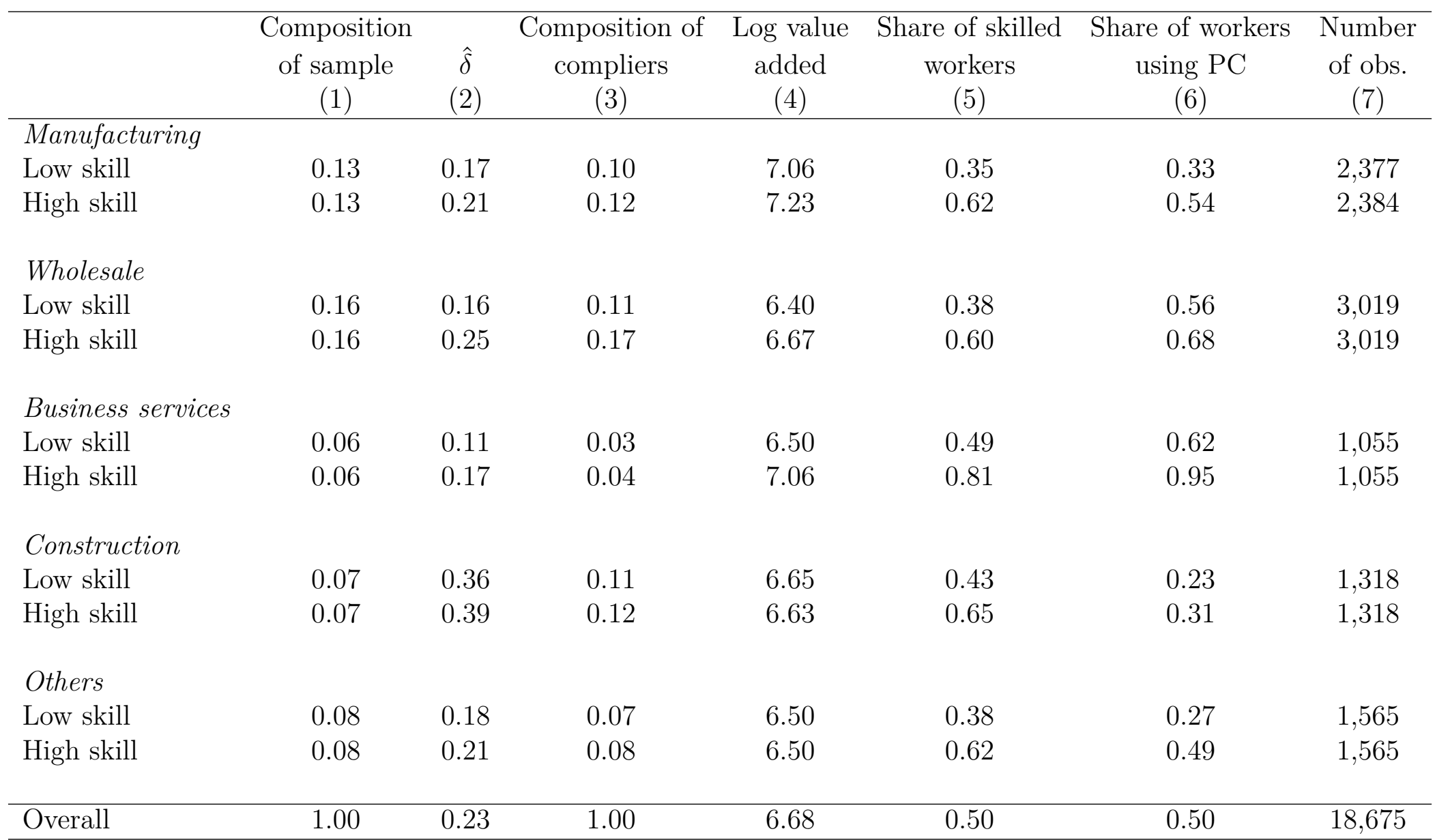

Note: We partition the baseline firm sample into ten mutually exclusive groups by industry and share of workers with high school diploma (above and below median within each industry). Column (1) displays the proportion of the sample in each industry-skill group. Column (2) reports estimates of $\delta$ from equation 9 for each group. The proportion of the compliers of a given type is then calculated as the ratio of $\hat{\delta}$ for that subgroup to the $\hat{\delta}$ in the overall sample, multiplied by the proportion of the sample in the industry-skill group. Column (3) shows the distribution of the compliers by industry and skill intensity. Columns (4)-(6) report characteristics of each industry-skill group prior to the roll-out (in year 2000). Sampling weights are used to ensure representative results for the population of joint-stock firms. 


\subsection{Economic significance}

To put the size of our estimates into perspective, we calculate the counterfactual output elasticities and labor outcomes that would have occurred in the absence of the broadband expansion. A counterfactual outcome is measured as the actual outcome minus the predicted effect of broadband internet on the outcome (of compliers). Consider the predicted effect on the output elasticity of (un)skilled labor. In each year, we compute this as the broadband coverage rate $Z_{m t}$ multiplied by the coefficient $\delta$ on coverage rate in equation (9) times the coefficient on the interaction between broadband adoption and (un)skilled labor in equation (7). Similarly, the predicted effect on (un)skilled wages or employment is calculated as the broadband coverage rate times the coefficient $\gamma_{S}\left(\gamma_{U}\right)$ on the interaction between broadband coverage and (un)skilled in equation (8).

Panel (a) of Figure 5 shows the actual time trends for the estimated output elasticties, as well as the predicted counterfactual time trends. While these graphs are based on the LP estimates, the trends change little if we instead use the IV estimates. The output elasticity of skilled labor has increased over time, in part because of the expansion of broadband coverage. By comparison, unskilled workers experienced an initial decline in their labor productivity due to the expansion of broadband internet. In the last year of our sample, we predict the output elasticity of (un)skilled workers would have been 0.34 instead of 0.30 (0.23 instead of 0.24 ) in the absence of the broadband expansion.

Panels (b) and (c) of Figure 5 show similar graphs for employment rates and hourly wages. Due to a sluggish Norwegian economy, the employment rates are declining between 2000 and 2004. While the expansion of broadband internet mitigates the fall in employment rates among skilled workers, unskilled workers experience a larger decline than in the absence of the expansion. In 2005, for example, the employment rate for (un)skilled workers was $1.3(0.9)$ percentage points higher (lower) than it otherwise would have been. By comparison, hourly wages increase throughout our sample period. In 2007, our estimates suggest the wages are (2.8\% lower) $1.4 \%$ higher for (un)skilled workers than they would have been in the absence of the broadband expansion.

\subsection{Implications for TFP}

Another way to quantify the importance of productivity-influencing factors is to compare the dispersion in TFP estimates from production functions with and without these factors (see e.g. Syverson, 2011). We examine the contribution from broadband internet by comparing the results from a standard production function:

$$
y_{i m k t}=x_{i m k t}^{\prime} \beta_{0}+\eta_{m}+\tau_{t}+\lambda_{k}+\nu_{i m k t}
$$


Figure 5. Economic significance of changes in output elasticities and labor outcomes

(a) Output elasticities
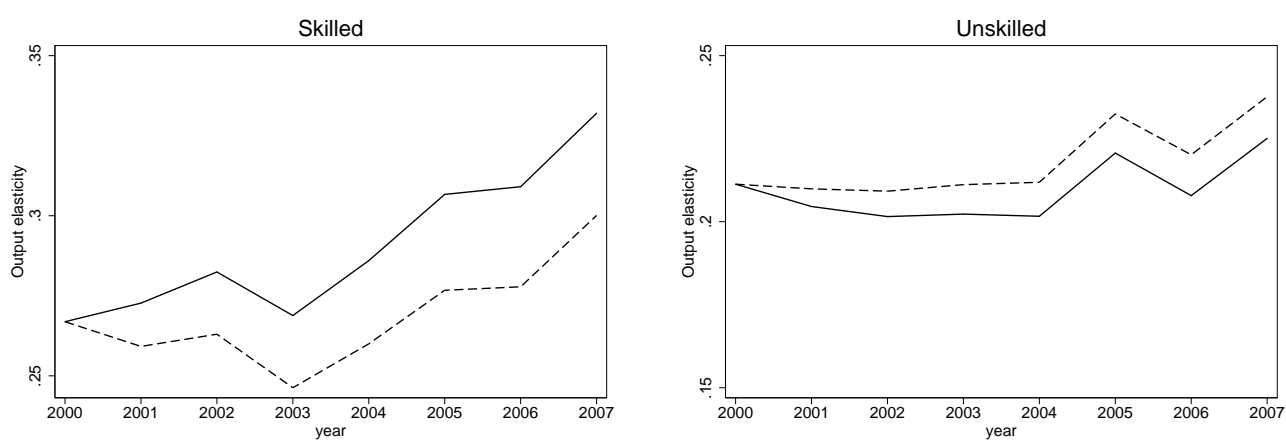

(b) Employment rates
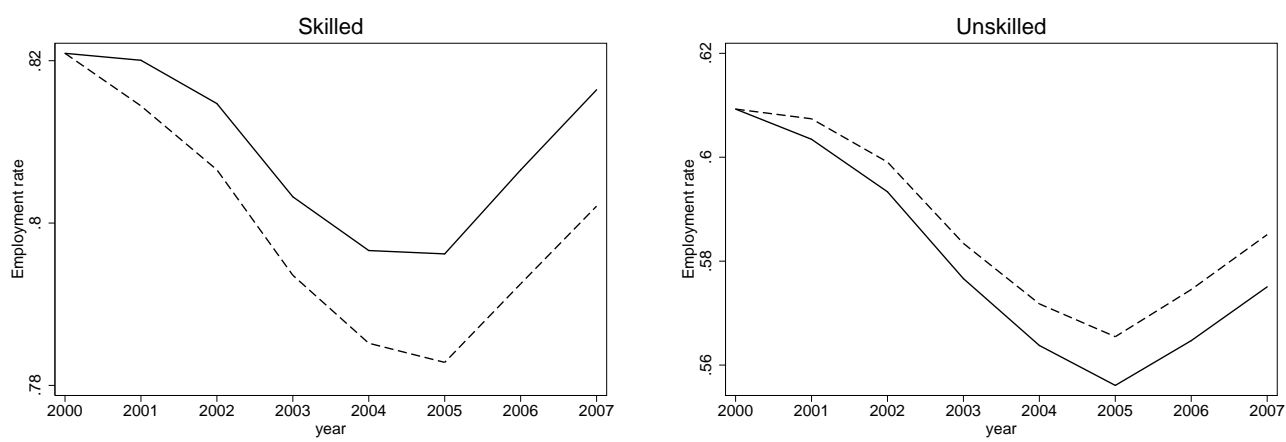

(c) Log hourly wages
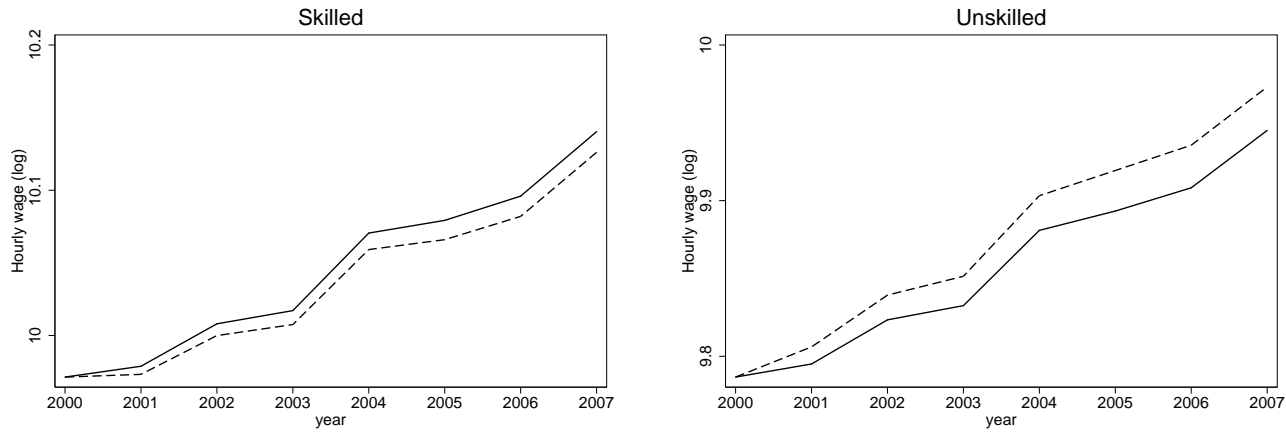

Note: Solid line $=$ actual outome. Dashed line $=$ counterfactual outcome in the absence of broadband internet expansion.

A counterfactual outcome is measured as the actual outcome minus the predicted effect of broadband internet on the outcome. In each year, we compute the predicted effect on the output elasticity of (un)skilled labor as the broadband coverage rate $Z_{m t}$ multiplied by the coefficient $\delta$ on coverage rate in equation 9 times the coefficient on the interaction between broadband adoption and (un)skilled labor in equation (7). In each year, we compute the predicted effect on (un)skilled wages or employment as the broadband coverage rate times the coefficient $\gamma_{S}\left(\gamma_{U}\right)$ on the interaction between broadband coverage and (un)skilled in equation (8). 
Table 7. Dispersion of TFP with and without broadband internet

\begin{tabular}{lcccccc}
\hline & \multicolumn{6}{c}{ Production function estimation: } \\
\cline { 2 - 7 } & \multicolumn{3}{c}{ OLS } & IV & \multicolumn{3}{c}{ LP } \\
Bithout & With & Without & With & Without \\
Broadband internet: & $(1)$ & $(2)$ & $(3)$ & $(4)$ & With \\
\hline & & & & & 1.12 & 1.06 \\
Standard deviation & 0.84 & 0.77 & 0.84 & 0.82 & 2.04 & 2.00 \\
90/50 percentiles & 1.73 & 1.70 & 1.73 & 1.71 & 1.96 & 1.96 \\
50/10 percentiles & 1.61 & 1.59 & 1.61 & 1.61 & \\
\hline
\end{tabular}

Note: Baseline firm sample over the period 2001-2007, consisting of 18,675 joint-stock firms recorded in the internet survey. Sampling weights are used to ensure representative results for the population of joint-stock firms. Columns (1), (3) and (5) report results in the case where TFP is constructed from the production function in equation 10 without broadband internet. Columns (2), (4) and (5) report results in the case where TFP is constructed from the production function in equation (3) with broadband internet. Standard deviation measures dispersion across firms from their average TFP. 90/50 and 50/10 ratios refer to percentiles in the distribution of TFP across firms.

to those produced by equation (3) where we allow broadband internet to shift the production technology. We define

$$
\begin{aligned}
A_{i t}^{0} & \equiv e^{\hat{\nu}_{i m k t}} \\
A_{i t}^{1} & \equiv e^{\hat{\varepsilon}_{i m k t}}
\end{aligned}
$$

as measures of TFP in firms according to the specification with $\left(A_{i t}^{1}\right)$ and without $\left(A_{i t}^{0}\right)$ broadband adoption in the production function.

To measure the extent to which broadband internet accounts for firm productivity, we compare the dispersion of $A_{i t}^{0}$ and $A_{i t}^{1}$ across firms in our baseline sample. The results are reported in Table 7 . Given that equation (3) nests equation (10), we expect less dispersion in $A_{i t}^{1}$ as compared to $A_{i t}^{0}$. Indeed, the dispersion in TFP across firms is reduced by including broadband internet in the production function estimation. When applying the IV and LP estimates, we find the standard deviation in TFP declines from 0.84 to 0.82 (2.4 percent) and from 1.12 to 1.06 (5.3 percent), respectively. By comparing the 90/50 and 50/10 ratios, we find that broadband internet is more important in explaining differences in the upper part of the TFP distribution.

\subsection{Worker heterogeneity}

Our estimates of how broadband adoption affects productivity and labor outcomes are consistent with the widespread view that ICT is complementary with human capital; therefore, falls in quality-adjusted ICT prices increase skill demand and the returns to skill. We now explore what types of human capital that are complementary with broadband internet.

Since we have access to detailed information on educational attainment, we are able 
Table 8. Production function estimates with 3 skill categories and field of study

\begin{tabular}{lccc}
\hline & \multicolumn{3}{c}{ Production function } \\
\cline { 2 - 4 } & OLS & IV & LP \\
\hline Panel $A$ & & & \\
Internet $\times$ Unskilled & $-0.0338^{*}$ & $-0.103^{* *}$ & $-0.0832^{*}$ \\
Internet $\times$ Medium skilled & $(0.0190)$ & $(0.0523)$ & $(0.0427)$ \\
& $0.0404^{* * *}$ & 0.0209 & -0.0149 \\
Internet $\times$ High skilled & $(0.0137)$ & $(0.0465)$ & $(0.0372)$ \\
& $0.0856^{* * *}$ & $0.158^{* * *}$ & $0.126^{* * *}$ \\
& $(0.00761)$ & $(0.0438)$ & $(0.0360)$ \\
\hline Panel $B$ & & & \\
Internet $\times$ Unskilled & -0.00121 & $-0.190^{* *}$ & $-0.147^{*}$ \\
Internet $\times$ Medium skilled & $(0.0359)$ & $(0.0929)$ & $(0.0800)$ \\
& -0.00161 & 0.00285 & -0.0259 \\
Internet $\times$ High skilled low return field & $(0.0368)$ & $(0.0682)$ & $(0.0649)$ \\
& 0.0131 & 0.0735 & 0.0594 \\
Internet $\times$ High skilled high return field & $(0.0163)$ & $(0.0473)$ & $(0.0431)$ \\
& $0.0797^{* * *}$ & $0.208^{* * *}$ & $0.164^{* * *}$ \\
& $(0.0164)$ & $(0.0671)$ & $(0.0620)$ \\
\hline
\end{tabular}

Note: We restrict the baseline firm sample to firms with at least one employee in each skill category. As a result, Panel A (B) consists of $16,249(11,449)$ joint-stock firms recorded in the internet survey. Sampling weights are used to ensure representative results for the population of joint-stock firms with at least one employee in each skill category. Unskilled comprises workers without high school diploma; medium skilled consists of high school graduates (with no post-secondary education); high skilled includes individuals with post-secondary education. High return fields comprise science, technology, engineering, and social sciences including law and economics; low return fields include teaching, health, humanities, primary sector, transport and communication (for more details, see Appendix Table A5. The standard errors are clustered at the municipality level and robust to heteroskedasticity. All regressions include fixed effect for year, municipality and industry. 
Table 9. Wage regressions with 3 skill categories and field of study

\begin{tabular}{lcc}
\hline & $\begin{array}{c}\text { Employment rate } \\
(1)\end{array}$ & $\begin{array}{c}\text { Log hourly wage } \\
(2)\end{array}$ \\
\hline Panel A: & $-0.00782^{* * *}$ & $-0.0122^{* * *}$ \\
Cov $\times$ Unskilled & $(0.00251)$ & $(0.00323)$ \\
Cov $\times$ Medium skilled & 0.00322 & -0.00921 \\
Cov $\times$ High skilled & $(0.00252)$ & $(0.00600)$ \\
& $0.0245^{* * *}$ & $0.0221^{* * *}$ \\
& $(0.00787)$ & $(0.00736)$ \\
\hline Panel B: & & \\
Cov $\times$ Unskilled & $-0.00748^{* * *}$ & $-0.0102^{* * *}$ \\
Cov $\times$ Medium skilled & $(0.00254)$ & $(0.00373)$ \\
Cov $\times$ High skilled low return field & 0.00356 & -0.00734 \\
Cov $\times$ High skilled high return field & $(0.00259)$ & $(0.00666)$ \\
& $0.0185^{* * *}$ & $0.00749^{* *}$ \\
& $(0.00503)$ & $(0.00336)$ \\
& $0.0329^{* * *}$ & $0.0478^{* * *}$ \\
& $(0.0119)$ & $(0.0172)$ \\
\hline
\end{tabular}

Note: Baseline samples of labor outcomes over the period 2001-2007, consisting of all workers aged 18-67 who are recorded in the wage statistics survey (Column 1; 8,759,386 observations) and the full population of individuals between the ages of 18 and 67 (Column 2; 20,327,515 observations). All regressions include fixed effects for year, municipality and industry and controls for gender, years of experience and years of experience squared. Unskilled comprises individuals without high school diploma; medium skilled consists of high school graduates (with no post-secondary education); high skilled includes individuals with post-secondary education. High return fields comprise science, technology, engineering, and social sciences including law and economics; low return fields include teaching, health, humanities, primary sector, transport and communication (for more details, see Appendix Table A5. The standard errors are clustered at the municipality level and robust to heteroskedasticity. 
to make the distinction between high (post secondary education), middle (high school graduates) and low (without high school diploma) skilled labor. Moreover, we are able to differentiate between field of study among college graduates. To gain precision, we consider two types of college graduates: high return fields (consisting of science, technology, engineering, business and social sciences including law and economics) vs. low return fields (all other fields such as teaching, health, humanities, etc.). Appendix Table A5 forms the basis for the categorization of fields of study by their returns, demonstrating that workers with high vs. low return fields had systematically different wages prior to the expansion of broadband internet.

Table 8 reports production function estimates where we differentiate between three levels of education as well as field of study among college graduates. ${ }^{27}$ Panel A suggests the skill complementarity of broadband internet mainly pertains to workers with postsecondary education. Panel B shows the increase in labor productivity is especially strong for college graduates in high return fields. In Table 9, we augment the wage regression in equation (8) to include three levels of skills and interactions between high skilled and field of study. Consistent with the estimated changes in output elasticities, we find the gains of broadband internet are largest for college graduates in high return fields.

\section{Mechanisms}

We explore several channels through which broadband internet can affect labor productivity and labor outcomes.

The first possible channel is that expansion of broadband internet changes demand for goods in favor of skilled labor. For example, broadband internet may facilitate e-commerce, either through online sales of final goods or online procurement of intermediate goods. To investigate this, we use information for our baseline sample of firms on whether they procure intermediate goods online or receive orders online. Using these variables as dependent variables, we estimate an IV model in which the second stage equation is

$$
Y_{i m k t}=\zeta D_{i m k t}+\eta_{m}+\tau_{t}+\lambda_{k}+\varepsilon_{i m k t},
$$

and the first stage equation is given by equation (9). Panel A of Appendix Table A6 reports the IV estimates. There is no evidence of a significant effect of broadband adoption on the probability of procuring online or receiving orders online. Another piece of evidence against this channel is provided in Appendix Table A9. In this table, we examine how broadband adoption affects labor productivity among firms in the tradeable sector where

\footnotetext{
${ }^{27}$ In Table 8 , we refine the baseline sample to be appropriate for the estimation of these production functions by focusing on firms with at least one employee in each skill category. As a result, Panel A consists of 16,249 firms, whereas Panel B uses 11,449 firms.
} 
demand is given by the world market ${ }^{28}$ Consistent with the baseline results, we find that broadband adoption increases (decreases) the productivity of (un)skilled labor.

A second possible channel is that our findings are driven by changes in labor productivity and wages in firms that may have been directly affected by the expansion of broadband access. However, both the output elasticities and the wage regression results barely move if we exclude telecom firms (including Telenor) or IT consultancy companies from the estimation sample (see Appendix Tables A7 and A8). It could also be that broadband adoption coincides with general technical upgrading in firms. For example, the estimated changes in labor productivity might be due to investments in computers at the time broadband is adopted. We investigate this by estimating equations (11) and (9) with the share of workers using PC as the dependent variable in the second stage. The IV estimate reported in Panel B of Appendix Table A6 does not support this channel.

Instead, our findings are consistent with the task approach to skill biased technological change. Starting with Autor, Levy, and Murnane (2003), a growing literature suggest that ICT substitutes for workers in performing routine tasks - more amenable to automatization - and complements workers in executing nonroutine abstract tasks. To explore this channel, we use the wage statistics surveys with information on occupation codes at the 4-digit level ${ }^{29}$ We link these occupation codes with job task requirements from the DOT data base provided by Autor and Dorn (2013). The measured job task intensities are (nonroutine) abstract tasks, routine tasks and (nonroutine) manual tasks 30

We find two pieces of evidence in support of the task based explanation of skill biased technological change. We first show that workers of different educational background indeed cluster disproportionately in occupations that require different tasks. Table 10 shows the occupational types, wages and task intensities for each skill category ${ }^{31}$ We find that college graduates tend to move into professional and managerial occupations that are pervasive at abstract tasks and pay more. The sorting is especially strong among individuals with college degrees in high return fields. By comparison, low educated workers are over-represented in poorly paid occupations that involve relatively little abstract tasks,

\footnotetext{
${ }^{28}$ Appendix Table A9 uses two measures of tradability. In Columns (1) and (2), we measure tradability in each 4-digit industry by dividing total levels of exports and imports by the value added of firms. In Columns (3) og (4), we follow Jensen and Kletzer (2005) in measuring tradability by the geographic concentration of an industry, defined as the Herfindahl index of employment shares across municipalities in each 4-digit industry. For both measures, we estimate the production function separately for firms in industries with values of tradability above and below the median in the baseline firm sample.

${ }^{29}$ We observe occupation codes for about $52 \%$ of the workers in the wage statistics surveys. As a result, Tables 10 and 11 are based on a subsample of the baseline sample used in the main wage regressions. When estimating the main wage regressions on this subsample, the conclusions about skill-biased technical change hold. Specifically, the estimated coefficient on the interaction between skilled and coverage rates moves from 0.0143 (s.e. $=0.008$ ) to 0.0135 (s.e. $=0.008$ ), whereas that for unskilled and coverage rates changes from -0.0281 (s.e. $=0.004)$ to -0.0423 (s.e. $=0.009$ ).

${ }^{30}$ See Autor, Levy, and Murnane (2003) and Autor and Dorn (2009) for detailed descriptions of how the task intensities are measured and intepreted.

${ }^{31}$ Following Autor and Dorn (2013), we define professional and managerial occupations as white-collar managerial, professional specialists, technical, finance, and public safety occupations.
} 
but require more routine or manual tasks.

Next, we estimate wage regressions which include interactions between broadband internet and the tasks performed in jobs rather than (or in addition to) the educational credentials of workers performing those jobs. All regressions control for time, municipality, and industry fixed effects as well as (potential) experience and gender. The estimates are provided in Table 11. Column 1 shows the expansion of broadband internet re-enforced the wage premiums to workers performing abstract tasks. By comparison, the wages paid to jobs requiring routine tasks declined because of the broadband expansion. The estimates imply that, holding everything else equal, a 10 percentage point increase in broadband coverage in a municipality raises (lowers) hourly wages of workers with abstract (routine) task intensity at the 75th percentile by 0.9 (0.2) percent, as compared to workers at the 25th percentile of the task intensity. Columns 2-4 show the estimates are quite similar when we control for skill levels and their interaction with broadband coverage. Taken together, the results presented in Tables 10 and 11 suggest an important channel behind the skill bias of broadband internet is that it complements non-routine abstract tasks but substitutes for routine tasks whilst not affecting manual tasks. 
Table 10. Occupation types, wages and task intensities by skill category.

\begin{tabular}{|c|c|c|c|c|c|c|c|c|}
\hline & \multicolumn{2}{|c|}{ Occupation types } & \multicolumn{3}{|c|}{ Mean relative wage } & \multicolumn{2}{|c|}{ Relative task intensities } & \multirow{4}{*}{$\begin{array}{c}\text { Number } \\
\text { of obs. }\end{array}$} \\
\hline & \multicolumn{2}{|c|}{ Professional \& } & \multicolumn{3}{|c|}{ Professional \& } & \multirow{3}{*}{$\begin{array}{c}\hat{M} / \hat{A} \\
(6)\end{array}$} & \multirow{3}{*}{$\begin{array}{c}\hat{R} / \hat{A} \\
(7)\end{array}$} & \\
\hline & Managerial & Other & All & Managerial & Other & & & \\
\hline & $(1)$ & $(2)$ & $(3)$ & (4) & $(5)$ & & & \\
\hline \multicolumn{9}{|l|}{ A. 2 skill categories } \\
\hline Unskilled & 0.12 & 0.88 & -0.13 & 0.16 & -0.17 & 0.15 & 0.24 & $1,730,625$ \\
\hline Skilled & 0.41 & 0.59 & 0.08 & 0.29 & -0.07 & -0.09 & -0.14 & $2,855,708$ \\
\hline \multicolumn{9}{|l|}{ B. 3 skill categories } \\
\hline Unskilled & 0.12 & 0.88 & -0.13 & 0.16 & -0.17 & 0.15 & 0.24 & $1,730,625$ \\
\hline Medium skilled & 0.17 & 0.83 & -0.05 & 0.22 & -0.10 & 0.11 & 0.18 & $1,446,022$ \\
\hline High skilled & 0.66 & 0.34 & 0.21 & 0.30 & 0.02 & -0.30 & -0.47 & $1,409,686$ \\
\hline \multicolumn{9}{|c|}{ C. 3 skill categories with low/high return fields } \\
\hline Unskilled & 0.12 & 0.88 & -0.13 & 0.16 & -0.17 & 0.15 & 0.24 & $1,730,625$ \\
\hline Medium skilled & 0.17 & 0.83 & -0.05 & 0.22 & -0.10 & 0.11 & 0.18 & $1,446,022$ \\
\hline High skilled low return field & 0.68 & 0.32 & 0.09 & 0.15 & -0.05 & 0.03 & -0.30 & 613,708 \\
\hline High skilled high return field & 0.65 & 0.35 & 0.30 & 0.43 & 0.07 & -0.55 & -0.61 & 795,978 \\
\hline
\end{tabular}

Note: We restrict the baseline worker sample to individuals for which we observe occupation code at the 4-digit level in the wage statistics surveys. The occupation codes are linked with measures of task intensity from the Dictionary of Occupational Title, as reported by Autor and Dorn (2013). Unskilled comprises individuals without high school diploma; medium skilled consists of high school graduates (with no post-secondary education); high skilled includes individuals with post-secondary education. High return fields comprise science, technology, engineering, and social sciences including law and economics; low return fields include teaching, health, humanities, primary sector, transport and communication. Columns (1) and (2) show the occupation distribution by skill category. Following Autor and Dorn (2013), we define professional and managerial occupations as white-collar managerial, professional specialists, technical, finance, and public safety occupations. Columns (3)-(5) provide mean relative wage by type of occupation and skill category. The mean relative wage is defined as the average $\log$ hourly wage within each skill-occupation group relative to the overall sample mean. Columns (6) and (7) report relative task intensities by skill level. Following Autor and Dorn 2009, 2013), we calculate $\hat{M} / \hat{A}(\hat{R} / \hat{A})$ as the mean of the logarithm of the ratio of the manual (routine) task content in an occupation to the abstract task content in the same occupation. Both measures are standardized with mean zero and variance one. 
Table 11. Wage regressions with task intensities

\begin{tabular}{|c|c|c|c|c|}
\hline \multirow[b]{2}{*}{ Dep. variable: Log hourly wage } & \multirow[b]{2}{*}{ (1) } & \multicolumn{3}{|c|}{ Skill categories } \\
\hline & & $\begin{array}{c}2 \text { skill levels } \\
\text { (2) }\end{array}$ & $\begin{array}{c}3 \text { skill levels } \\
\text { (3) }\end{array}$ & $\begin{array}{c}3 \text { skill levels and } \\
\text { low \& high return fields } \\
(4)\end{array}$ \\
\hline Abstract & $\begin{array}{l}0.364^{* * *} \\
(0.0143)\end{array}$ & $\begin{array}{l}0.326^{* * *} \\
(0.0137)\end{array}$ & $\begin{array}{l}0.265^{* * *} \\
(0.0142)\end{array}$ & $\begin{array}{l}0.271^{* * *} \\
(0.0139)\end{array}$ \\
\hline Routine & $\begin{array}{c}-0.0579^{* * *} \\
(0.00605)\end{array}$ & $\begin{array}{c}-0.0627^{* * *} \\
(0.00575)\end{array}$ & $\begin{array}{c}-0.0633^{* * *} \\
(0.00534)\end{array}$ & $\begin{array}{c}-0.0583^{* * *} \\
(0.00500)\end{array}$ \\
\hline Manual & $\begin{array}{l}0.0287^{* * *} \\
(0.00785)\end{array}$ & $\begin{array}{l}0.0241^{* * *} \\
(0.00756)\end{array}$ & $\begin{array}{l}0.0169^{* *} \\
(0.00726)\end{array}$ & $\begin{array}{l}0.0181^{* * *} \\
(0.00642)\end{array}$ \\
\hline Coverage $\times$ Abstract & $\begin{array}{c}0.178^{* * *} \\
(0.0325)\end{array}$ & $\begin{array}{c}0.170^{* * *} \\
(0.0293)\end{array}$ & $\begin{array}{c}0.161^{* * *} \\
(0.0300)\end{array}$ & $\begin{array}{r}0.158^{* * *} \\
(0.0291)\end{array}$ \\
\hline Coverage $\times$ Routine & $\begin{array}{c}-0.0347^{* * *} \\
(0.00740)\end{array}$ & $\begin{array}{c}-0.0358^{* * *} \\
(0.00750)\end{array}$ & $\begin{array}{c}-0.0340^{* * *} \\
(0.00737)\end{array}$ & $\begin{array}{c}-0.0340^{* * *} \\
(0.00739)\end{array}$ \\
\hline Coverage $\times$ Manual & $\begin{array}{c}-0.00183 \\
(0.0121)\end{array}$ & $\begin{array}{l}-0.00100 \\
(0.0117)\end{array}$ & $\begin{array}{c}-0.000867 \\
(0.0107)\end{array}$ & $\begin{array}{c}0.00859 \\
(0.00930)\end{array}$ \\
\hline Controls: & & & & \\
\hline $\begin{array}{l}\text { Skill categories } \\
\text { Coverage*Skill category }\end{array}$ & & $\begin{array}{l}\sqrt{ } \\
\sqrt{ }\end{array}$ & $\begin{array}{l}\sqrt{ } \\
\sqrt{ }\end{array}$ & $\begin{array}{l}\sqrt{ } \\
\sqrt{ }\end{array}$ \\
\hline
\end{tabular}

Note: We restrict the baseline worker sample to individuals for which we observe occupation code at the 4-digit level in the wage statistics surveys (4,586,333 observations). The occupation codes are linked with measures of task intensity from the Dictionary of Occupational Title (DOT), as reported by Autor and Dorn (2013). Following Autor, Levy, and Murnane (2003), we convert the DOT measures into percentiles of the task distribution. Unskilled comprises individuals without high school diploma; medium skilled consists of high school graduates (with no post-secondary education); high skilled includes individuals with post-secondary education. High return fields comprise science, technology, engineering, and social sciences including law and economics; low return fields include teaching, health, humanities, primary sector, transport and communication. Column (1) presents results from a regression of log hourly wages on task intensities and their interaction with broadband coverage in the local labor market. Column (2) adds indicator variables for two levels of skill and their interaction with broadband coverage. Column 3 includes indicator variables for three levels of skills and their interaction with broadband coverage. Column (4) includes indicator variables for three levels of skill, high return and low return field of study, and their interaction with broadband coverage. All regressions include fixed effects for year, municipality and industry, and controls for gender, years of experience and years of experience squared. Standard errors are heteroskedasticity robust and clustered at the municipality level. 


\section{Conclusion}

In 2009, the U.S. Congress asked for a plan that would provide affordable broadband service to all America's citizens. In other OECD countries, there has been similar calls for public funding to roll out broadband infrastructure. While government agencies are projecting broadband penetration rates to be important for productivity and job creation, there is little scientific evidence to substantiate these claims. We contribute by examining how adoption of broadband internet in firms shifts their production technology and changes the productivity and labor outcomes of different types of workers. Our analysis employs several data sources from Norway that we can link through unique firm and individual identifiers. Using firm-level information on value added, capital, labor by skill level and broadband adoption, we estimate production functions where firms can change their technology by adopting broadband internet. We complement these production function estimates with wage regressions which include interactions between broadband internet and skill levels. A public program with limited funding rolled out broadband access points, and provides plausibly exogenous variation of broadband adoption in firms.

We find that broadband adoption favors skilled labor over unskilled labor by increasing its relative productivity. The estimated increase in productivity of skilled labor is especially large for college graduates in high return fields such as science, technology, engineering and business. By comparison, broadband internet is a substitute for workers without high school diploma, lowering their marginal productivity. Consistent with the estimated changes in labor productivity, wage regressions show that the expansion of broadband internet improves (worsens) the labor outcomes of skilled (unskilled) workers. We explore several possible explanations for the skill-bias of broadband internet. We find suggestive evidence that broadband internet complements skilled workers in executing nonroutine abstract tasks, and substitutes for unskilled workers in performing routine tasks. When we use our production function estimates to construct measures of firm level productivity, we find that broadband internet accounts for a few percent of the standard deviation in total factor productivity across firms.

Taken together, these findings have important implications for the debate about the role of government policies in encouraging productivity growth. Our estimates suggest that policy increasing the broadband penetration rates could enhance firm productivity. A related issue is why policy changes, even if they encourage productivity, do not always happen. One explanation is that established interests earning rents in the unreformed environment could be able to stave off reform. Examining who wins, who loses, and by how much could inform about the nature of these barriers and how to design compensation schemes. Our study points to the skill bias of broadband induced shift in production technology as a barrier to government investment in broadband infrastructure. 


\section{References}

Acemoglu, D. (2003): "Patterns of Skill Premia," Review of Economic Studies, 70(2), 199-230.

Acemoglu, D., And D. H. Autor (2011): "Skills, Tasks and Technologies: Implications for Employment and Earnings," in Handbook of Labor Economics Vol. 4, ed. by O. Ashenfelter, and D. E. Card, chap. 12, pp. 1043-1171. Elsevier, Amsterdam.

Atkinson, A. B., L. Rainwater, and T. M. Smeeding (1995): Income Distribution in OECD Countries: Evidence from the Luxembourg Income Study. Organisation for Economic Co-operation and Development Paris.

Autor, D. H., And D. Dorn (2009): "This Job is 'Getting Old': Measuring Changes in Job Opportunities using Occupational Age Structure," American Economic Review: Papers 83 Proceedings, 99(2), 45-51.

(2013): "The Growth of Low-Skill Service Jobs and the Polarization of the US Labor Market," American Economic Review, 103(5), 1553-1597.

Autor, D. H., L. F. Katz, and M. S. Kearney (2006): "The Polarization of the U.S. Labor Market," American Economic Review Papers and Proceedings, 96(2), 189-194.

(2008): "Trends in US Wage Inequality: Revising the Revisionists," Review of Economics and Statistics, 90(2), 300-323.

Autor, D. H., L. F. Katz, and A. B. Krueger (1998): "Computing Inequality: Have Computers Changed the Labor Market?," Quarterly Journal of Economics, 113(4), 1169-1213.

Autor, D. H., F. Levy, and R. J. Murnane (2003): "The Skill Content of Recent Technological Change: An Empirical Exploration," Quarterly Journal of Economics, 118(4), 1279-1333.

Beaudry, P., M. Doms, and E. Lewis (2010): "Should the Personal Computer Be Considered a Technological Revolution? Evidence from U.S. Metropolitan Areas," Journal of Political Economy, 118(5), 988 - 1036.

Beaudry, P., And D. A. Green (2003): "The Changing Structure of Wages in the US and Germany: What Explains the Differences?," American Economic Review, 93(3), $573-602$.

(2005): "Changes in U.S. Wages, 1976-2000: Ongoing Skill Bias or Major Technological Change?," Journal of Labor Economics, 23(3), 609-648. 
Berman, E. (2000): "Does Factor-Biased Technological Change Stifle International Convergence? Evidence from Manufacturing," NBER Working Paper 7964.

Berman, E., J. Bound, and Z. Griliches (1994): "Changes in the Demand for Skilled Labor within US Manufacturing: Evidence from the Annual Survey of Manufactures," Quarterly Journal of Economics, 109(2), 367-397.

Bhuller, M., T. Havnes, E. Leuven, and M. Mogstad (forthcoming): "Broadband Internet: An Information Superhighway to Sex Crime?," Review of Economic Studies.

Black, S. E., And A. Spitz-Oener (2010): "Explaining Women's Success: Technological Change and the Skill Content of Women's Work," Review of Economics and Statistics, 92(1), 187-194.

Bloom, N., L. Garicano, R. Sadun, and J. Van Reenen (2009): "The Distinct Effects of Information Technology and Communication Technology on Firm Organization," NBER Working Paper 14975.

Bloom, N., R. Sadun, and J. Van Reenen (2012): "Americans Do IT Better: US Multinationals and the Productivity Miracle," American Economic Review, 102(1), $167-201$.

Bond, S., And J. VAn Reenen (2007): "Microeconometric Models of Investment and Employment," in Handbook of Econometrics, ed. by J. J. Heckman, and E. E. Leamer, pp. 4417-4498. North Holland, London.

Bresnahan, T. F., E. Brynjolfsson, and L. M. Hitt (2002): "Information Technology, Workplace Organization, and the Demand for Skilled Labor: Firm-level evidence," Quarterly Journal of Economics, 117(1), 339-376.

Brynjolfsson, E., And L. M. Hitt (2003): "Computing Productivity: Firm-level Evidence," Review of Economics and Statistics, 85(4), 793-808.

Caroli, E., and J. Van Reenen (2001): "Skill Biased Organizational Change? Evidence from a Panel of British and French Establishments," Quarterly Journal of Economics, 116(4), 1449-1492.

Czernich, N., O. Falck, T. Kretschmer, and L. Woessmann (2011): "Broadband Infrastructure and Economic Growth," Economic Journal, 121(May), 505-532.

DiNardo, J. E., And J.-S. Pischke (1997): "The Returns to Computer Use Revisited: Have Pencils Changed the Wage Structure Too?," Quarterly Journal of Economics, 112(1), 291-303. 
Draca, M., R. Sadun, and J. Van Reenen (2007): "Productivity and ICTs: A Review of the Evidence," in Oxford Handbook of Information and Communication Technologies, ed. by R. Mansell, C. Avgerou, D. Quah, and R. Silverstone, pp. 100-147. Oxford University Press.

Firpo, S., N. M. Fortin, And T. Lemieux (2011): "Occupational Tasks and Changes in the Wage Structure," IZA Discussion Paper 5542.

Forman, C., A. Goldfarb, and S. Greenstein (2012): "The Internet and Local Wages: A Puzzle," American Economic Review, 102(1), 556-575.

Fox, J. T., And V. SmeEts (2011): "Does Input Quality Drive Measured Differences In Firm Productivity?," International Economic Review, 52(4), 961-989.

Goldin, C., And L. F. KAtz (2007): "Long-Run Changes in the Wage Structure: Narrowing, Widening, Polarizing," Brookings Papers on Economic Activity, 38(2), $135-168$.

Goos, M., And A. Manning (2007): "Lousy and Lovely Jobs: The Rising Polarization of Work in Britain," Review of Economics and Statistics, 89(1), 118-133.

Holm, S. (1979): "A Simple Sequentially Rejective Multiple Test Procedure," Scandinavian Journal of Statistics, 6(2), 65-70.

Imbens, G. W., And J. D. Angrist (1994): "Identification and Estimation of Local Average Treatment Effects," Econometrica, 62(2), 467-475.

Jensen, J. B., And L. G. Kletzer (2005): "Tradable Services: Understanding the Scope and Impact of Services Outsourcing," Institute for International Economics Working Paper 05-9.

Jorgenson, D. W., M. S. Ho, And K. J. Stiroh (2008): "A Retrospective Look at the U.S. Productivity Growth Resurgence," Journal of Economic Perspectives, 22(1), $3-24$.

Krueger, A. B. (1993): "How Computers Have Changed the Wage Structure: Evidence from Microdata, 1984-1989," Quarterly Journal of Economics, 108(1), 33-60.

Levinsohn, J., And A. Petrin (2003): "Estimating Production Functions Using Inputs to Control for Unobservables," Review of Economic Studies, 70(2), 317-341.

Machin, S., And J. VAn ReEnen (1998): "Technology and Changes in Skill Structure: Evidence from Seven OECD Countries," Quarterly Journal of Economics, 113(4), 12151244. 
Michaels, G., A. Natraj, and J. Van Reenen (forthcoming): "Has ICT Polarized Skill Demand? Evidence from Eleven Countries over 25 years," Review of Economics and Statistics.

Oliner, S. D., D. E. Sichel, And K. J. Stiroh (2007): "Explaining a Productive Decade," Brookings Papers on Economic Activity, 38(1), 81-152.

Olley, S. G., And A. Pakes (1996): "The Dynamics of Productivity in the Telecommunications Equipment Industry,” Econometrica, 64(6), 1263-1297.

PAvCnIK, N. (2002): "Trade Liberalization, Exit, and Productivity Improvements: Evidence from Chilean plants," Review of Economic Studies, 69(1), 245-276.

ST.MELD.NR. 38 (1997-1998): "IT-kompetanse i et regionalt perspektiv [A regional perspective on IT-competency]," Ministry of Trade and Industry.

ST.MELD.NR. 49 (2003): "Breiband for kunnskap og vekst [Broadband for knowledge and growth]," Ministry of Trade and Industry.

Syverson, C. (2011): "What Determines Productivity?," Journal of Economic Literature, 49(2), 326-365.

Van Beveren, I. (2012): "Total Factor Productivity Estimation: A Practical Review," Journal of Economic Surveys, 26(1), 98-128. 


\section{Appendix A: Additional Tables and Figures}

Figure A1. Distribution of firms by industry

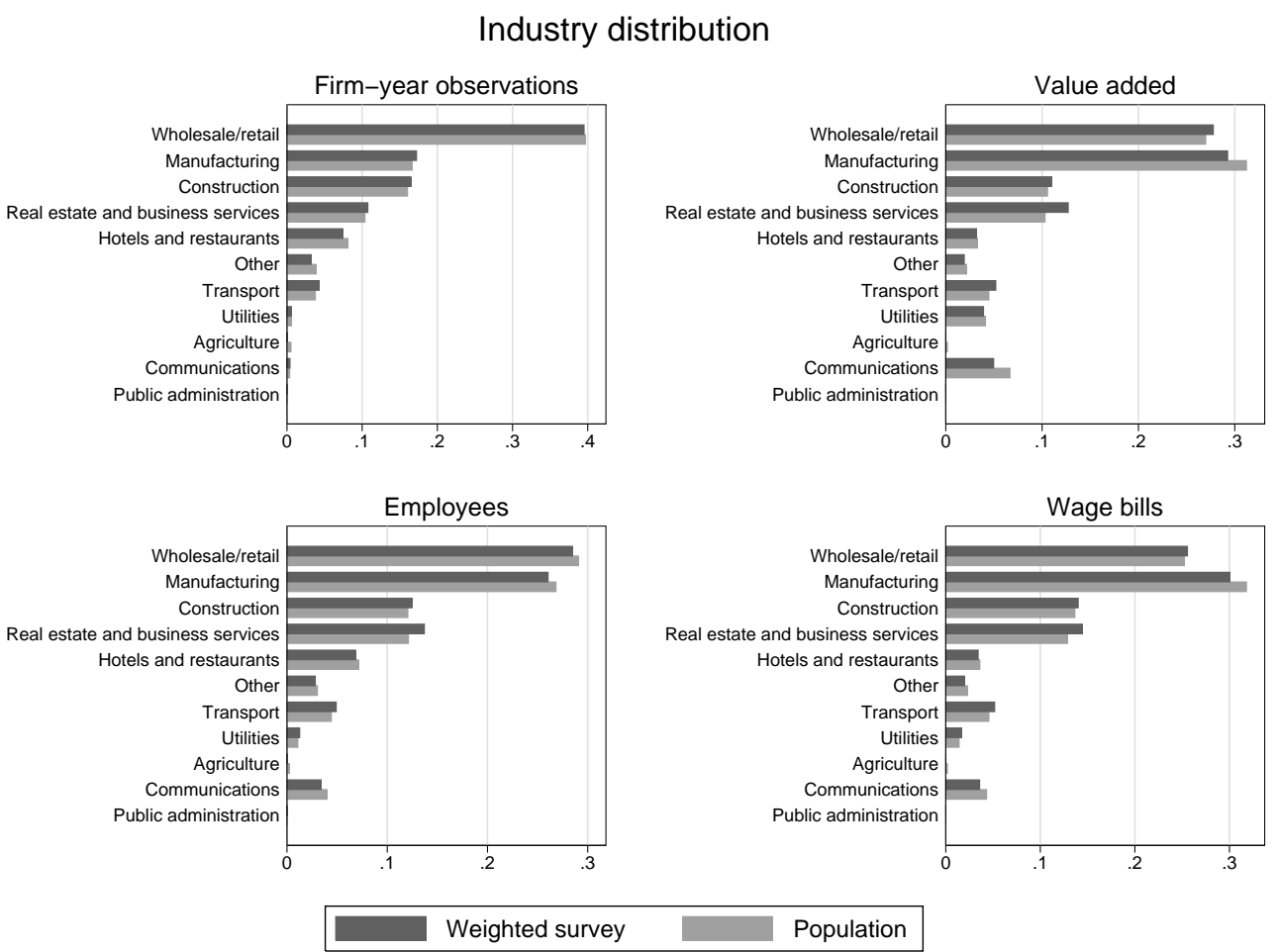

Note: The survey sample consists of joint-stock firms recorded in the internet survey. Sampling weights are used to ensure representative results for the population of joint-stock firms. We exclude firms that are carrying out extraction of natural resources (including oil, gas and fish). 
Figure A2. Cross-sectional distribution of key firm variables

\section{Input-output}
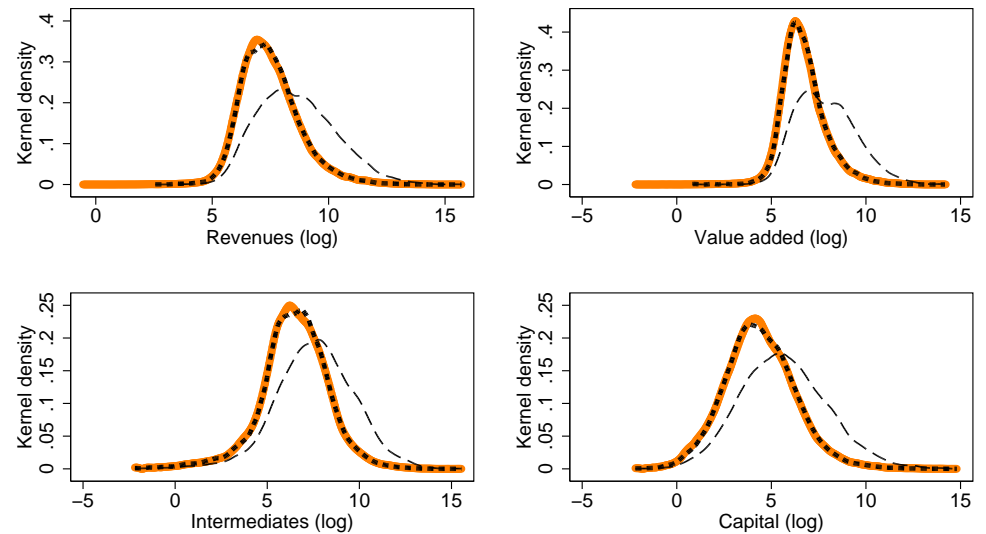

Wage bills
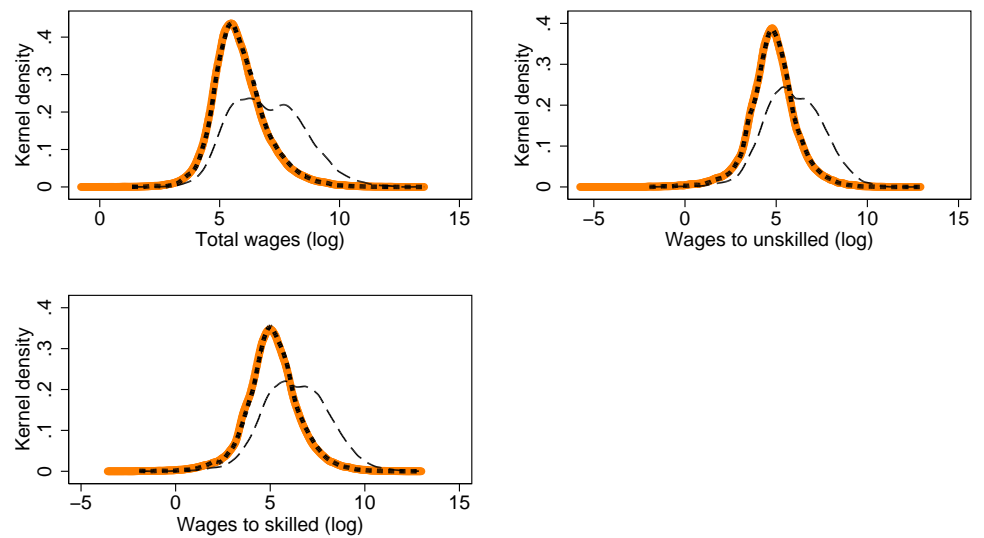

Number of workers
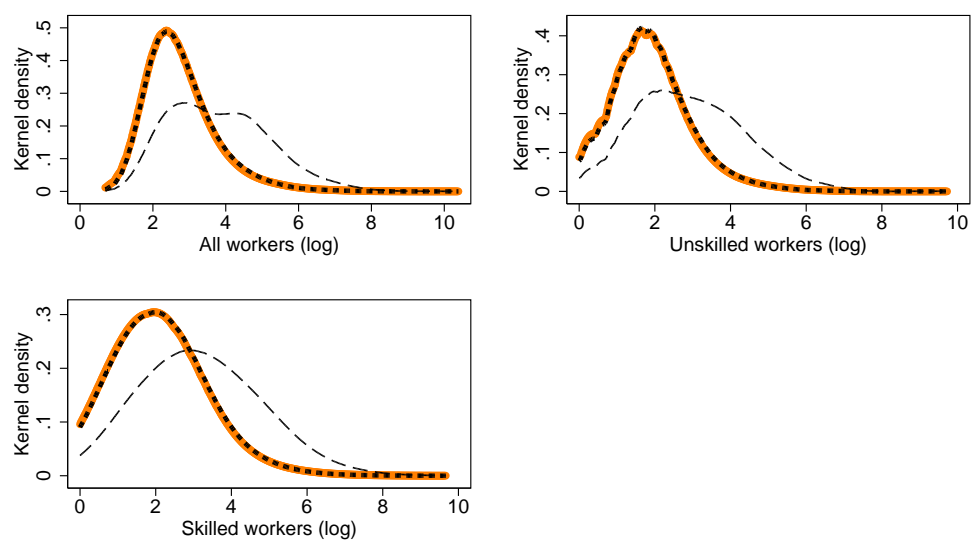

Population

Weighted survey

Note: The survey sample consists of joint-stock firms recorded in the internet survey over the period 2001-2007. The weighted survey uses sampling weights to ensure representative results for the population of joint-stock firms. We exclude firms that are carrying out extraction of natural resources (including oil, gas and fish). Detailed descriptions of the variables are given in Appendix Table A1. 
Figure A3. Time trends in key firm variables

\section{Input-output}
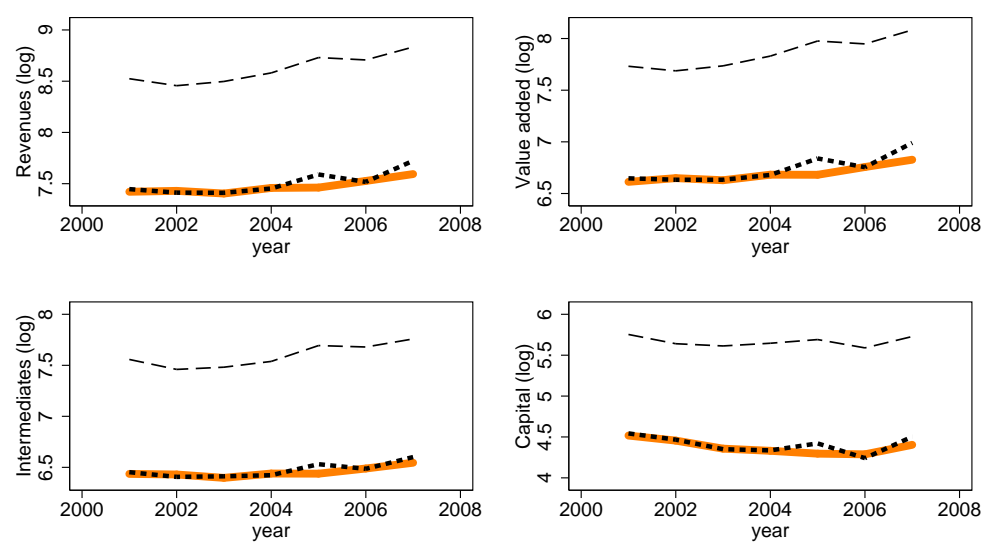

Wage bills
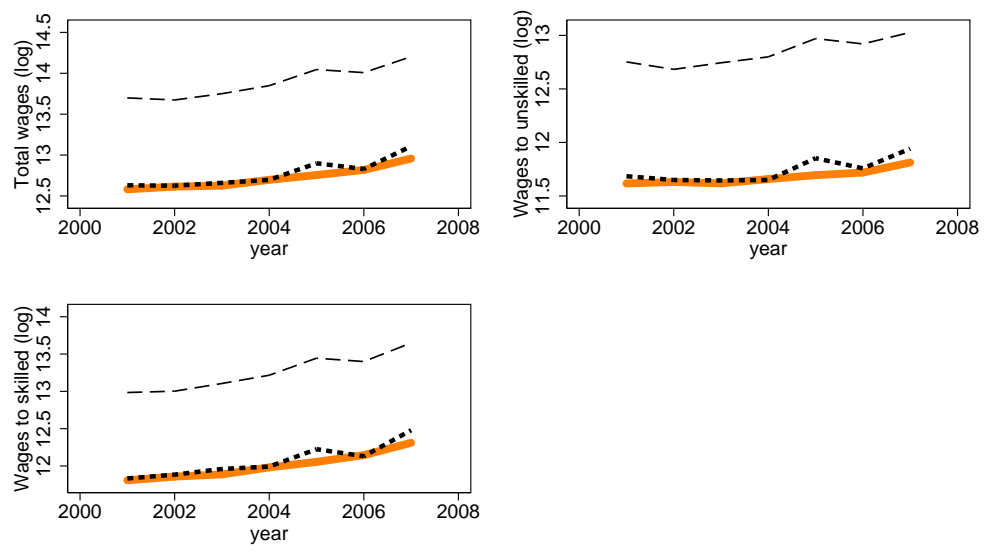

\section{Number of workers}
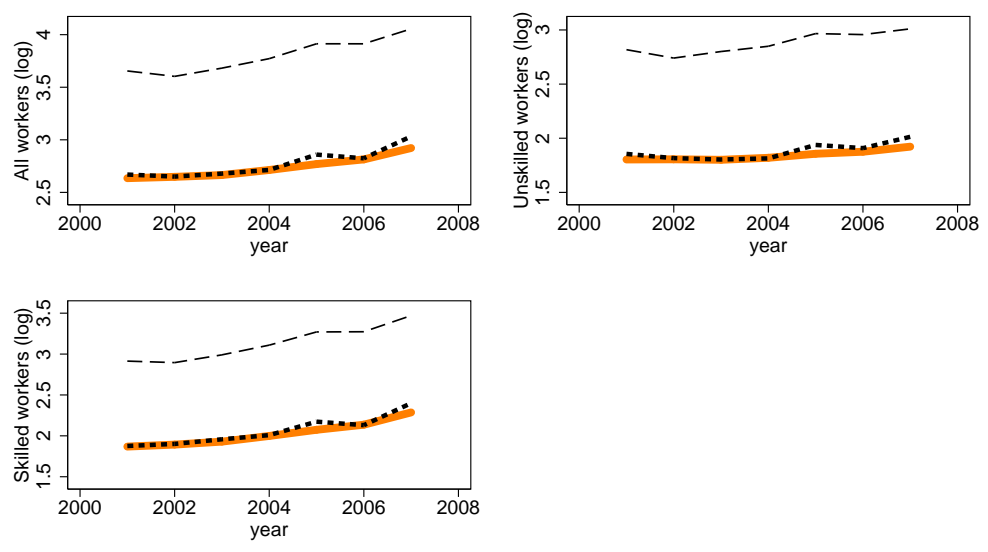

Population ......... Weighted survey

Note: The survey sample consists of joint-stock firms recorded in the internet survey over the period 2001-2007. The weighted survey uses sampling weights to ensure representative results for the population of joint-stock firms. We exclude firms that are carrying out extraction of natural resources (including oil, gas and fish). Detailed descriptions of the variables are given in Appendix Table A1 
Figure A4. Geographical distribution of broadband coverage rates.
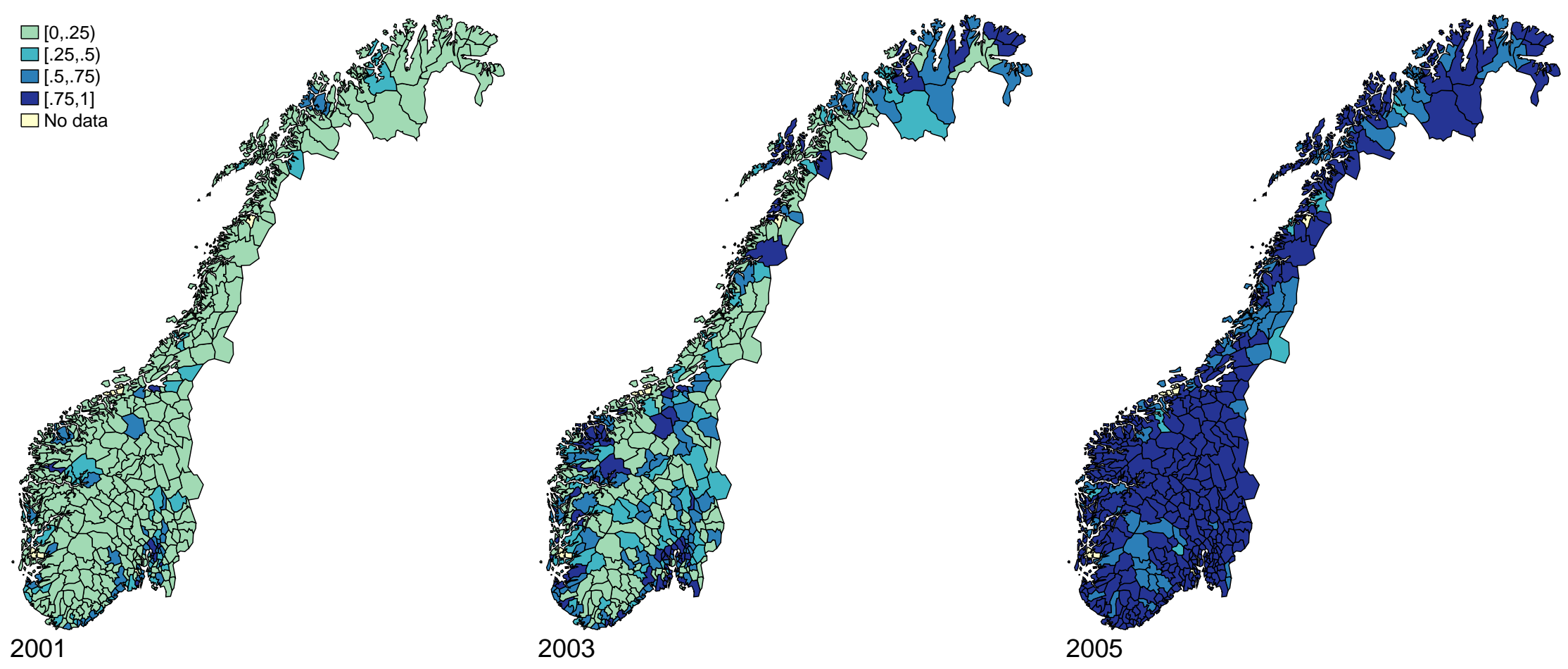

Note: The graphs show the geographical distribution of broadband coverage rates of households in 2001, 2003 and 2005. 
Figure A5. Timing of broadband expansion and baseline covariates
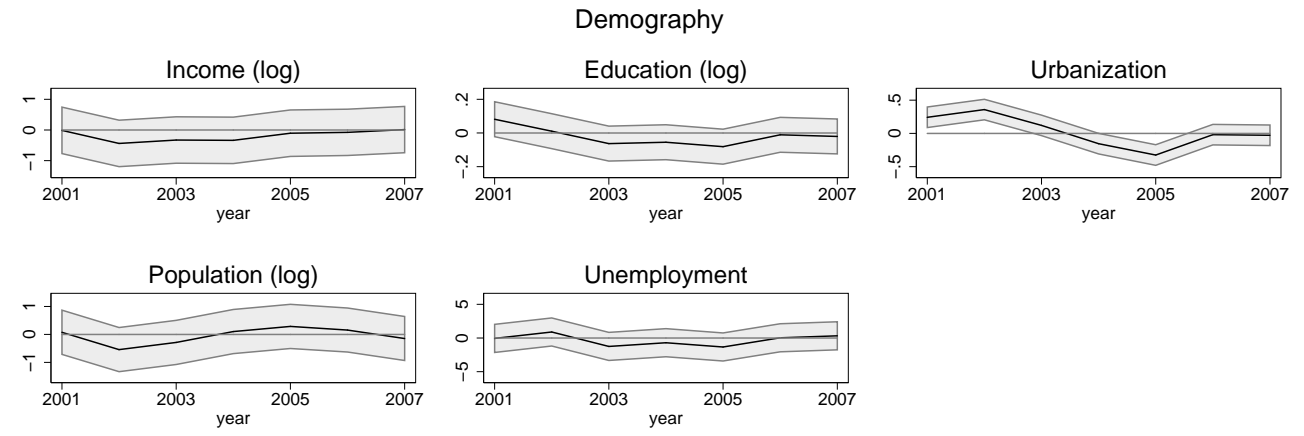

Input and output
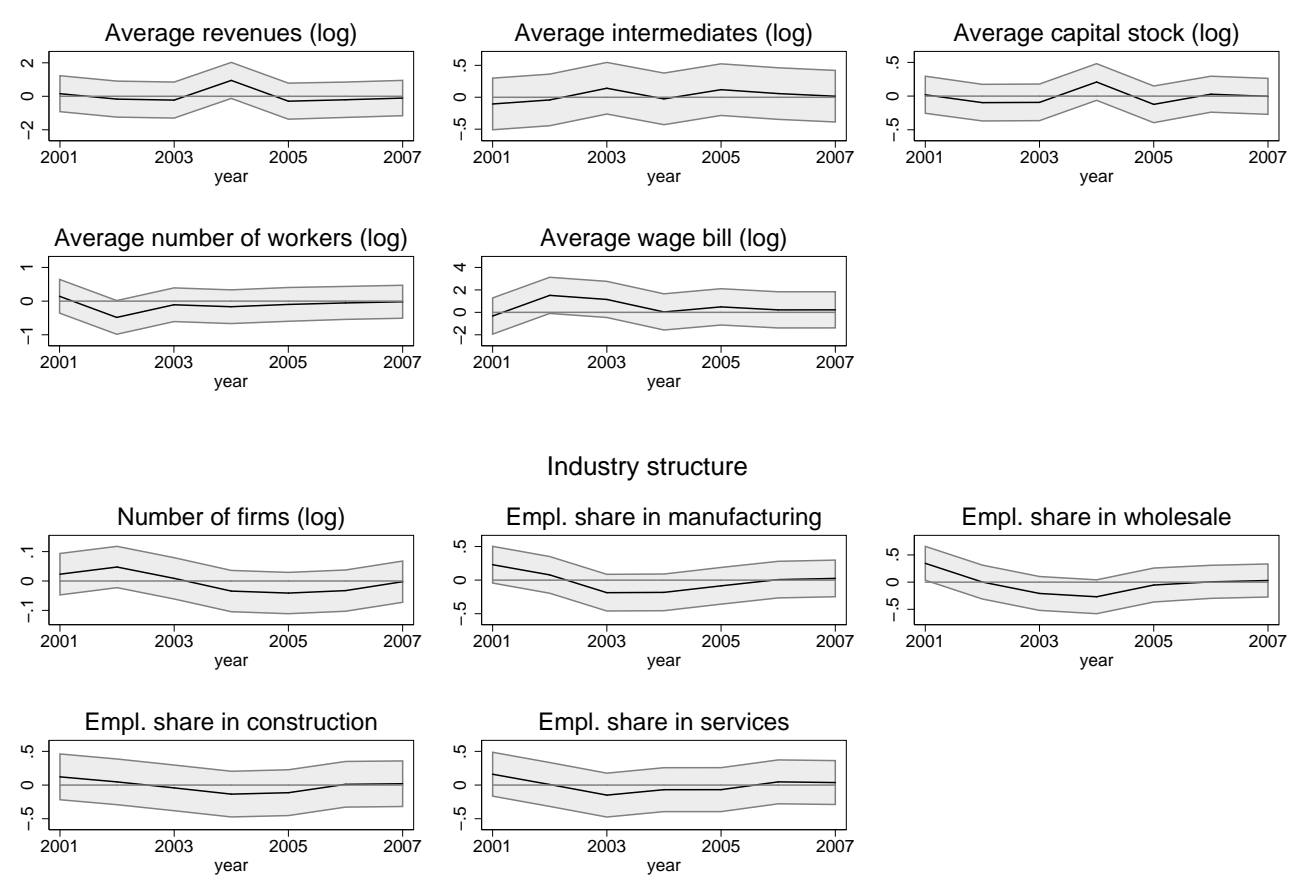

Skill structure
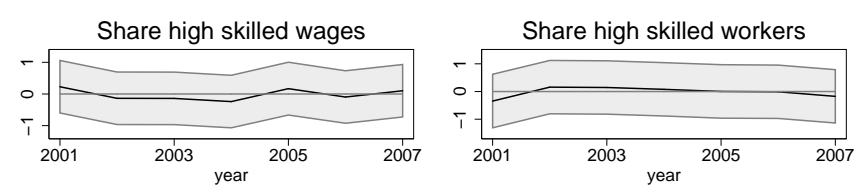

Note: We report estimates from equation 5 of the vector $\psi_{t}$ for every $t$ (and the associated $95 \%$ confidence intervals). Demography includes income level, education, share of population residing in a densely populated locality (an urbanization indictor), size of population and level of unemployment. As measures of industry structure, we use number of firms, employment share in manufacturing, employment share in wholesale, and employment share in services. For inputs and output we have included municipality averages of revenues, intermediates, capital stock, number of workers and wage bill. 
Figure A6. Period-specific LP estimates of output elasticities, pre and post expansion

(a) Output elasticity: Skilled labor

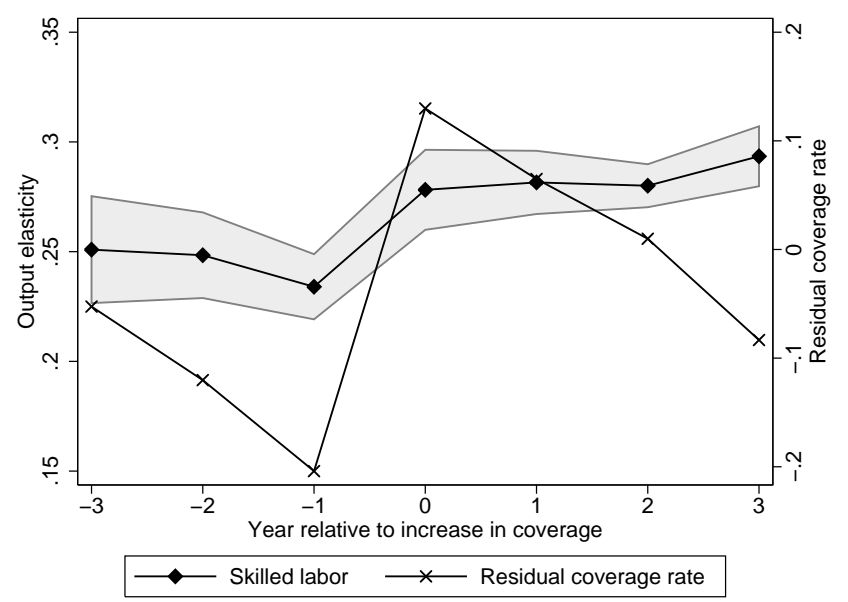

(b) Output elasticity: Unskilled labor

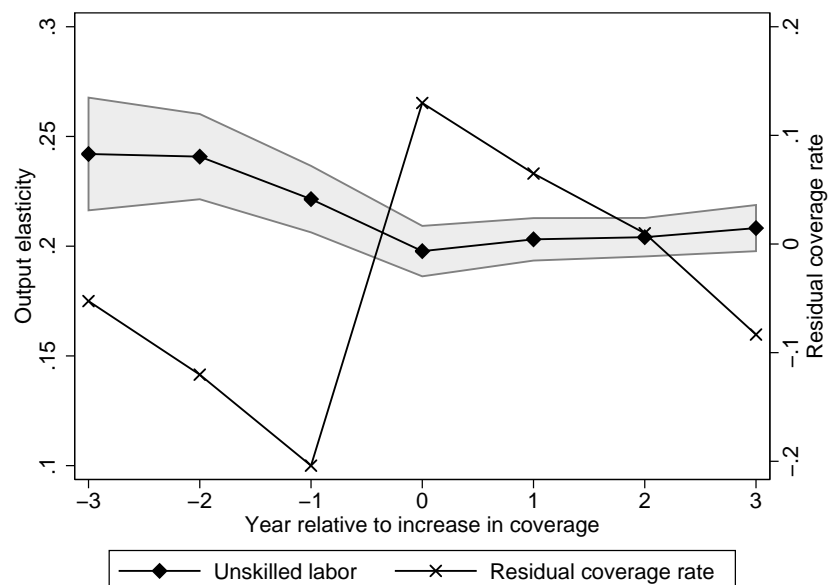

Note: Baseline firm sample over the period 2001-2007, consisting of joint-stock firms recorded in the internet survey. Sampling weights are used to ensure representative results for the population of joint-stock firms. Coverage rates are residuals from a regression of municipality-level broadband coverage on municipality, industry and year fixed effects. Time zero represents the year with the strongest growth in residual coverage rates in a given municipality. In each time period, we estimate production functions while controlling for municipality, industry and year fixed effects. Graphs (a) and (b) report period-specific LP estimates of the output elasticity of skilled and unskilled labor. The grey areas show $95 \%$ confidence intervals. 
Table A1. Variable definitions

\begin{tabular}{|c|c|}
\hline Variable & Description \\
\hline Firm accounts & Source: The Account Statistics. \\
\hline Revenues & Total sales by a firm in year $t$. \\
\hline Intermediates & Procurement of materials and intermediate inputs of a firm in year $t$. \\
\hline Capital & Value of total fixed assets of a firm in year $t$. \\
\hline Value added & Sales minus intermediates of a firm in year $t$. \\
\hline Industry & $\begin{array}{l}\text { 4-digit code classifying a firm's main activity in year } t \text { according to the } \\
\text { Standard Industry Classification (SIC2002) system. }\end{array}$ \\
\hline Municipality & 4-digit code for the municipality in which a firm is located in year $t$. \\
\hline Exports & Total value of exported goods of a firm in year $t$. \\
\hline Imports & Total value of imported goods of a firm in year $t$. \\
\hline Internet variables & Source: The community survey on ICT in firms \\
\hline Broadband & $\begin{array}{l}\text { Dummy variable for whether a firm has adopted broadband internet } \\
\text { (speed at or above } 256 \text { kilobits per second) in year } t \text {. }\end{array}$ \\
\hline $\begin{array}{l}\text { Procurement } \\
\text { done online }\end{array}$ & $\begin{array}{l}\text { Dummy variable for whether a firm conducts at least part of its } \\
\text { procurement online in year } t \text {. }\end{array}$ \\
\hline $\begin{array}{l}\text { Revenues from } \\
\text { online orders }\end{array}$ & $\begin{array}{l}\text { Dummy variable for whether at least part of a firm's total revenues } \\
\text { comes from online orders in year } t \text {. }\end{array}$ \\
\hline Employees & $\begin{array}{l}\text { Source: Register of Employers and Employees and the Wage Statistics } \\
\text { Survey. }\end{array}$ \\
\hline Annual wages & Annual pre-tax wages in year $t$ \\
\hline $\begin{array}{l}\text { Employment } \\
\text { status }\end{array}$ & $\begin{array}{l}\text { Dummy variable for whether annual wages exceed the substantial } \\
\text { gainful activity threshold in year } t \text { (USD } 6,850 \text { in 2001), which defines } \\
\text { employment in the Social Security System. }\end{array}$ \\
\hline Hourly wages & Hourly pre-tax wage per October in year $t$. \\
\hline Occupation & 4-digit occupation code of a job in year $t$. \\
\hline $\begin{array}{l}\text { Individual } \\
\text { characteristics }\end{array}$ & Source: National Education Database and Central Population Register. \\
\hline Education level & Years of schooling. \\
\hline Field of study & Post-secondary field of study. \\
\hline Municipality & Municipality of residence in year t. \\
\hline Age & The age of a worker in year $t$. \\
\hline $\begin{array}{l}\text { Potential } \\
\text { experience }\end{array}$ & Age in year $t$ - years of schooling - 7 \\
\hline Gender & The gender of a worker. \\
\hline
\end{tabular}




\begin{tabular}{|c|c|}
\hline Variable & Description \\
\hline Internet coverage & Source: Norwegian Ministry of Government Administration. \\
\hline Coverage rate & $\begin{array}{l}\text { Fraction of households in a given municipality with access to broadband } \\
\text { internet (speed at or above } 256 \text { kilobits per second) in year } t \text {. }\end{array}$ \\
\hline $\begin{array}{l}\text { Demographic } \\
\text { controls }\end{array}$ & Source: Central Population Register. \\
\hline Urbanization & $\begin{array}{l}\text { Population share living in densely populated area in a given } \\
\text { municipality in year } t \text {. }\end{array}$ \\
\hline Income & $\begin{array}{l}\text { Average annual disposable income across individuals aged } 16-59 \text { years } \\
\text { in a given municipality in year } t \text {. }\end{array}$ \\
\hline Education & $\begin{array}{l}\text { Average years of schooling across individuals aged 16-59 in a given } \\
\text { municipality in year } t \text {. }\end{array}$ \\
\hline Unemployment & $\begin{array}{l}\text { Unemployment rate among individuals aged } 16-59 \text { in a given } \\
\text { municipality in year } t \text {. }\end{array}$ \\
\hline Industry and firm & Source: The Account Statistics and Register of Employers and \\
\hline controls & Employees. \\
\hline $\begin{array}{l}\text { Share of skilled } \\
\text { workers }\end{array}$ & $\begin{array}{l}\text { Share of employed workers with high school diploma in a given } \\
\text { municipality in year } t \text {. }\end{array}$ \\
\hline $\begin{array}{l}\text { Share of total } \\
\text { wages to skilled } \\
\text { workers }\end{array}$ & $\begin{array}{l}\text { Share of the total wage bill paid to workers with high school diploma in } \\
\text { a given municipality in year } t \text {. }\end{array}$ \\
\hline $\begin{array}{l}\text { Share of } \\
\text { employment by } \\
\text { industry }\end{array}$ & $\begin{array}{l}\text { Share of workers in the manufacturing/wholesale/service industry in a } \\
\text { given municipality in year } t \text {. }\end{array}$ \\
\hline $\begin{array}{l}\text { Average input } \\
\text { levels }\end{array}$ & $\begin{array}{l}\text { Average level of capital stock/value added/number of workers/wages } \\
\text { paid/revenues across firms in a given municipality in year } t \text {. }\end{array}$ \\
\hline
\end{tabular}


Table A2. Production function estimates without broadband internet

\begin{tabular}{lccccc}
\hline & \multicolumn{2}{c}{ OLS } & & \multicolumn{2}{c}{ LP } \\
\cline { 2 - 3 } \cline { 5 - 6 } Panel B: 1 skill category & Population & Weighted Survey & & Population & Weighted Survey \\
Capital & $0.0818^{* * *}$ & $0.0891^{* * *}$ & & $0.124^{* * *}$ & $0.1888^{* * *}$ \\
Labor & $(0.00297)$ & $(0.00474)$ & & $(0.020)$ & $(0.018)$ \\
& $0.825^{* * *}$ & $0.833^{* * *}$ & & $0.620^{* * *}$ & $0.650^{* * *}$ \\
\hline Panel B: 2 skill categories & $(0.00299)$ & $(0.00741)$ & & $(0.00418)$ & $(0.00991)$ \\
Capital & $0.103^{* * *}$ & $0.110^{* * *}$ & & $0.142^{* * *}$ & $0.225^{* * *}$ \\
& $(0.00333)$ & $(0.00555)$ & & $(0.023)$ & $(0.019)$ \\
Unskilled & $0.295^{* * *}$ & $0.301^{* * *}$ & & $0.210^{* * *}$ & $0.225^{* * *}$ \\
& $(0.00508)$ & $(0.00898)$ & & $(0.00375)$ & $(0.00703)$ \\
Skilled & $0.421^{* * *}$ & $0.423^{* * *}$ & & $0.295^{* * *}$ & $0.303^{* * *}$ \\
& $(0.00805)$ & $(0.0155)$ & & $(0.00665)$ & $(0.0149)$ \\
\hline Observations & 192,312 & 18,675 & 192,312 & 18,675 \\
\hline
\end{tabular}

Note: The survey sample consists of joint-stock firms recorded in the internet survey over the period 2001-2007. Sampling weights are used to ensure representative results for the population of joint-stock firms. (Un)Skilled comprises workers with(out) high school diploma. The standard errors are clustered at the municipality level and robust to heteroskedasticity. All regressions include fixed effect for year, municipality and industry. 
Table A3. Descriptive statistics of baseline sample

\begin{tabular}{lcccc}
\hline & 2001 & 2004 & 2007 & Total \\
\hline Employment rate & $($ level $)$ & $($ level $)$ & $($ level $)$ & $($ level $)$ \\
\hline Total & 0.72 & 0.70 & 0.72 & 0.71 \\
& $(0.45)$ & $(0.46)$ & $(0.45)$ & $(0.45)$ \\
Unskilled & 0.60 & 0.56 & 0.58 & 0.58 \\
Skilled & $(0.49)$ & $(0.50)$ & $(0.49)$ & $(0.49)$ \\
& 0.82 & 0.80 & 0.82 & 0.81 \\
Hourly wage & $(0.38)$ & $(0.40)$ & $(0.39)$ & $(0.39)$ \\
\hline Total & $(\log )$ & $(\log )$ & $(\log )$ & $(\log )$ \\
& 2.95 & 3.05 & 3.12 & 3.04 \\
Unskilled & $(0.27)$ & $(0.28)$ & $(0.30)$ & $(0.30)$ \\
Skilled & 2.83 & 2.92 & 2.98 & 2.91 \\
& $(0.21)$ & $(0.22)$ & $(0.23)$ & $(0.24)$ \\
Number of individuals, aged 18-67 & 3.02 & 3.11 & 3.18 & 3.10 \\
Number of workers in wage survey, aged 18-67 & $(0.28)$ & $(0.29)$ & $(0.30)$ & $(0.31)$ \\
\hline
\end{tabular}

Note: (Un)Skilled comprises workers with(out) high school diploma. Detailed descriptions of the variables are given in Appendix Table A1 
Table A4. First stage regressions: 2 skill categories.

\begin{tabular}{|c|c|c|c|c|c|}
\hline & Dependent variable: & $\begin{array}{l}\text { Internet } \\
\text { (1) }\end{array}$ & $\begin{array}{c}\text { Internet } \times \\
\text { Capital } \\
(2)\end{array}$ & $\begin{array}{c}\text { Internet } \times \\
\text { Unskilled } \\
(3)\end{array}$ & $\begin{array}{c}\text { Internet } \times \\
\text { Skilled } \\
(4)\end{array}$ \\
\hline \multirow{15}{*}{$\begin{array}{l}\text { Panel A: } \\
\text { IV }\end{array}$} & \multirow{2}{*}{ Capital } & $0.0237 * * *$ & $0.223^{* * *}$ & $0.294^{* * *}$ & $0.283^{* * *}$ \\
\hline & & $(0.00810)$ & $(0.0454)$ & $(0.0937)$ & $(0.0949)$ \\
\hline & \multirow[t]{2}{*}{ Unskilled } & $0.0341^{* * *}$ & $0.236^{* * *}$ & $0.527^{* * *}$ & $0.485^{* * *}$ \\
\hline & & $(0.0122)$ & $(0.0585)$ & $(0.134)$ & $(0.146)$ \\
\hline & \multirow[t]{2}{*}{ Skilled } & $0.0596^{* * *}$ & $0.392^{* * *}$ & $0.784^{* * *}$ & $0.877^{* * *}$ \\
\hline & & $(0.0136)$ & $(0.0647)$ & $(0.160)$ & $(0.168)$ \\
\hline & \multirow[t]{2}{*}{ Coverage } & $0.589 * * *$ & $1.709^{* *}$ & -0.270 & 0.393 \\
\hline & & $(0.167)$ & $(0.806)$ & $(1.964)$ & $(1.987)$ \\
\hline & \multirow[t]{2}{*}{ Coverage $\times$ Capital } & $-0.0159^{*}$ & $0.609^{* * *}$ & $-0.192^{*}$ & -0.176 \\
\hline & & $(0.00928)$ & $(0.0500)$ & $(0.109)$ & $(0.110)$ \\
\hline & \multirow[t]{2}{*}{ Coverage $\times$ Unskilled } & $-0.0294^{* *}$ & $-0.167^{* *}$ & $0.317^{*}$ & $-0.355^{* *}$ \\
\hline & & $(0.0150)$ & $(0.0690)$ & $(0.162)$ & $(0.177)$ \\
\hline & \multirow[t]{2}{*}{ Coverage $\times$ Skilled } & 0.00536 & -0.114 & 0.0206 & $0.620 * * *$ \\
\hline & & $(0.0171)$ & $(0.0745)$ & $(0.198)$ & $(0.202)$ \\
\hline & F-value (instruments) & 18.3 & 48.8 & 14.3 & 13.0 \\
\hline \multirow{15}{*}{$\begin{array}{l}\text { Panel B: } \\
\text { LP }\end{array}$} & \multirow[t]{2}{*}{ Capital } & $0.0589^{* *}$ & $-0.227^{* *}$ & $0.551^{*}$ & $0.504^{*}$ \\
\hline & & $(0.0247)$ & $(0.113)$ & $(0.282)$ & $(0.295)$ \\
\hline & \multirow[t]{2}{*}{ Unskilled } & $0.0251^{* *}$ & $0.169^{* * *}$ & $0.409 * * *$ & $0.352^{* *}$ \\
\hline & & $(0.0122)$ & $(0.0575)$ & $(0.133)$ & $(0.146)$ \\
\hline & \multirow[t]{2}{*}{ Skilled } & $0.0493^{* * *}$ & $0.310^{* * *}$ & $0.643^{* * *}$ & $0.717^{* * *}$ \\
\hline & & $(0.0136)$ & $(0.0645)$ & $(0.159)$ & $(0.166)$ \\
\hline & \multirow[t]{2}{*}{ Coverage } & $0.596^{* * *}$ & $1.936^{* *}$ & 0.0365 & 0.824 \\
\hline & & $(0.166)$ & $(0.790)$ & $(1.955)$ & $(1.976)$ \\
\hline & \multirow[t]{2}{*}{ Coverage $\times$ Capital } & -0.0143 & $0.602^{* * *}$ & $-0.182^{*}$ & -0.168 \\
\hline & & $(0.00910)$ & $(0.0479)$ & $(0.106)$ & $(0.107)$ \\
\hline & \multirow[t]{2}{*}{ Coverage $\times$ Unskilled } & $-0.0277^{*}$ & $-0.170 * *$ & $0.329^{* *}$ & $-0.344^{*}$ \\
\hline & & $(0.0150)$ & $(0.0669)$ & $(0.161)$ & $(0.176)$ \\
\hline & \multirow[t]{2}{*}{ Coverage $\times$ Skilled } & 0.00256 & $-0.128^{*}$ & -0.0204 & $0.571^{* * *}$ \\
\hline & & $(0.0169)$ & $(0.0734)$ & $(0.196)$ & $(0.199)$ \\
\hline & F-value (instruments) & 18.8 & 51.8 & 15.0 & 13.5 \\
\hline
\end{tabular}

Note: Baseline firm sample over the period 2001-2007, consisting of 18,675 joint-stock firms recorded in the internet survey. Sampling weights are used to ensure representative results for the population of joint-stock firms. (Un)Skilled comprises workers with(out) high school diploma. The standard errors are clustered at the municipality level and robust to heteroskedasticity. Panel A (B) provides the first stage results for the IV (LP) method. 
Table A5. Wage regressions with educationan levels and fields of study

\begin{tabular}{lcc}
\hline Dependent variable: & \multicolumn{2}{c}{ Log hourly wage } \\
\hline Medium skilled & $(1)$ & $(2)$ \\
& $0.0886^{* * *}$ & $0.0932^{* * *}$ \\
High skilled & $(0.00319)$ & $(0.00385)$ \\
& $0.296^{* * *}$ & $0.153^{* * *}$ \\
High skilled & $(0.00929)$ & $(0.0110)$ \\
interacted with: & & \\
Humanities & & \\
& & $0.0990^{* * *}$ \\
Teacher & & $(0.00819)$ \\
& & $0.0897^{* * *}$ \\
Social Sciences & & $(0.0134)$ \\
& & $0.223^{* * *}$ \\
Business & $(0.0113)$ \\
STEM & $0.215^{* * *}$ \\
& & $(0.0175)$ \\
Health & $0.259^{* * *}$ \\
Primary & $(0.00515)$ \\
Trans/Comm. & $0.0864^{* * *}$ \\
& & $(0.00916)$ \\
& & $0.174^{* * *}$ \\
& & $(0.0127)$ \\
& & $0.0820^{* * *}$ \\
& & $(0.00805)$ \\
\hline
\end{tabular}

Note: The sampel consists of workers recorded in the wage statistics survey in year 2000 (1,108,504 observations). We report results from regressions of log hourly wages in education levels and post-secondary fields of study. Unskilled comprises workers without high school diploma; medium skilled consists of high school graduates (with no post-secondary education); high skilled includes workers with post-secondary education. The reference category for education levels is unskilled workers. The reference category for field of study is "other/unspecified". All regressions include fixed effects for municipality and industry, and controls for gender, years of experience and years of experience squared. Standard errors are heteroskedasticity robust and clustered at the municipality level. 
Table A6. IV estimates of broadband adoption on E-commerce and computerization

\begin{tabular}{|c|c|c|}
\hline & $\begin{array}{l}\text { IV } \\
(1)\end{array}$ & $\begin{array}{c}\text { Dependent mean } \\
(2)\end{array}$ \\
\hline \multicolumn{3}{|l|}{ Panel A: E-commerce: } \\
\hline Dep. variable: Procuring online & $\begin{array}{l}0.0480 \\
(0.118)\end{array}$ & 0.50 \\
\hline Dep. variable: Receiving orders online & $\begin{array}{c}-0.00424 \\
(0.117)\end{array}$ & 0.24 \\
\hline \multicolumn{3}{|l|}{ Panel B: Technical upgrading } \\
\hline Dep. variable: Share of workers using a PC & $\begin{array}{l}-0.0199 \\
(0.0850)\end{array}$ & 0.53 \\
\hline
\end{tabular}

Note: Baseline firm sample over the period 2001-2007. Sampling weights are used to ensure representative results for the population of joint-stock firms. All regressions include fixed effect for year, municipality and industry. Standard errors are heteroskedasticity robust and clustered at the municipality level. The estimated coefficient on the instrument (broadband coverage) in the first stage regression is 0.23 with a standard error of 0.04 .

Table A7. Production function estimates excluding telecom firms and IT consultancy companies

\begin{tabular}{|c|c|c|c|c|}
\hline & & $\begin{array}{c}\text { Baseline } \\
(1)\end{array}$ & $\begin{array}{c}\text { No } \\
\text { telecom } \\
(2)\end{array}$ & $\begin{array}{c}\text { No IT } \\
\text { consultancy } \\
(3)\end{array}$ \\
\hline \multirow[t]{6}{*}{ IV } & \multirow[t]{2}{*}{ Internet $\times$ Capital } & -0.00741 & -0.00823 & -0.0121 \\
\hline & & $(0.0248)$ & $(0.0246)$ & $(0.0243)$ \\
\hline & \multirow[t]{2}{*}{ Internet $\times$ Unskilled } & -0.0553 & -0.0547 & -0.0518 \\
\hline & & $(0.0396)$ & $(0.0394)$ & $(0.0397)$ \\
\hline & \multirow{2}{*}{ Internet $\times$ Skilled } & $0.202^{* * *}$ & $0.202^{* * *}$ & $0.200 * * *$ \\
\hline & & $(0.0433)$ & $(0.0435)$ & $(0.0418)$ \\
\hline \multirow[t]{6}{*}{ LP } & \multirow[t]{2}{*}{ Internet $\times$ Capital } & -0.00701 & -0.00735 & -0.00999 \\
\hline & & $(0.0202)$ & $(0.0199)$ & $(0.0194)$ \\
\hline & \multirow[t]{2}{*}{ Internet $\times$ Unskilled } & $-0.0574^{*}$ & $-0.0581^{*}$ & -0.0543 \\
\hline & & $(0.0333)$ & $(0.0332)$ & $(0.0335)$ \\
\hline & \multirow{2}{*}{ Internet $\times$ Skilled } & $0.141^{* * *}$ & $0.140 * * *$ & $0.137^{* * *}$ \\
\hline & & $(0.0373)$ & $(0.0376)$ & $(0.0358)$ \\
\hline \multicolumn{2}{|l|}{$N$} & 18,675 & 18,520 & 18,192 \\
\hline
\end{tabular}

Note: Column 1 uses the baseline firm sample over the period 2001-2007, consisting of 18,675 joint-stock firms recorded in the internet survey. Column 2 excludes telecom firms (NACE code 64), whereas Column 3 excludes IT consultancy firms (NACE code 72). Sampling weights are used to ensure representative results for the corresponding population of joint-stock firms. (Un)Skilled comprises workers with(out) high school diploma. The standard errors are clustered at the municipality level and robust to heteroskedasticity. All regressions include fixed effect for year, municipality and industry. 
Table A8. Wage regression estimates excluding telecom firms and IT consultancy companies

\begin{tabular}{|c|c|c|c|c|}
\hline & & $\begin{array}{c}\text { Baseline } \\
\text { (1) }\end{array}$ & $\begin{array}{c}\text { No telecom } \\
\text { employees } \\
(2)\end{array}$ & $\begin{array}{c}\text { No computer } \\
\text { workers } \\
(3)\end{array}$ \\
\hline \multirow{5}{*}{$\begin{array}{l}\text { Panel } A \text { : } \\
\text { Employment rate }\end{array}$} & Cov $\times$ Unskilled & $-0.0101^{* * *}$ & $-0.00997 * * *$ & $-0.00959 * * *$ \\
\hline & & $(0.00262)$ & $(0.00262)$ & $(0.00261)$ \\
\hline & Cov $\times$ Skilled & $0.0144^{* * *}$ & $0.0141^{* * *}$ & $0.0147^{* * *}$ \\
\hline & & $(0.00491)$ & $(0.00479)$ & $(0.00500)$ \\
\hline & $N$ & $20,327,515$ & $20,049,183$ & $20,247,710$ \\
\hline \multirow{7}{*}{$\begin{array}{l}\text { Panel } B: \\
\text { Log hourly wage }\end{array}$} & Cov $\times$ Unskilled & $-0.0281^{* * *}$ & $-0.0286^{* * *}$ & $-0.0280 * * *$ \\
\hline & & $(0.00356)$ & $(0.00359)$ & $(0.00359)$ \\
\hline & Cov $\times$ Skilled & $0.0143^{*}$ & $0.0138^{*}$ & $0.0144^{*}$ \\
\hline & & $(0.00837)$ & $(0.00817)$ & $(0.00838)$ \\
\hline & $N$ & $8,759,386$ & $8,627,632$ & $8,679,582$ \\
\hline & Experience & $\sqrt{ }$ & $\sqrt{ }$ & $\sqrt{ }$ \\
\hline & Female & $\sqrt{ }$ & $\sqrt{ }$ & $\sqrt{ }$ \\
\hline
\end{tabular}

Note: Column 1 uses baseline samples of labor outcomes over the period 2001-2007. Column 2 excludes workers in telecom firms (NACE code 64), whereas Column 3 excludes workers in IT consultancy firms (NACE code 72). (Un)Skilled comprises workers with(out) high school diploma. The standard errors are clustered at the municipality level and robust to heteroskedasticity. All regressions include fixed effects for year, municipality and industry and controls for gender, years of experience and years of experience squared. 
Table A9. Production function estimates in tradable and non-tradable sectors

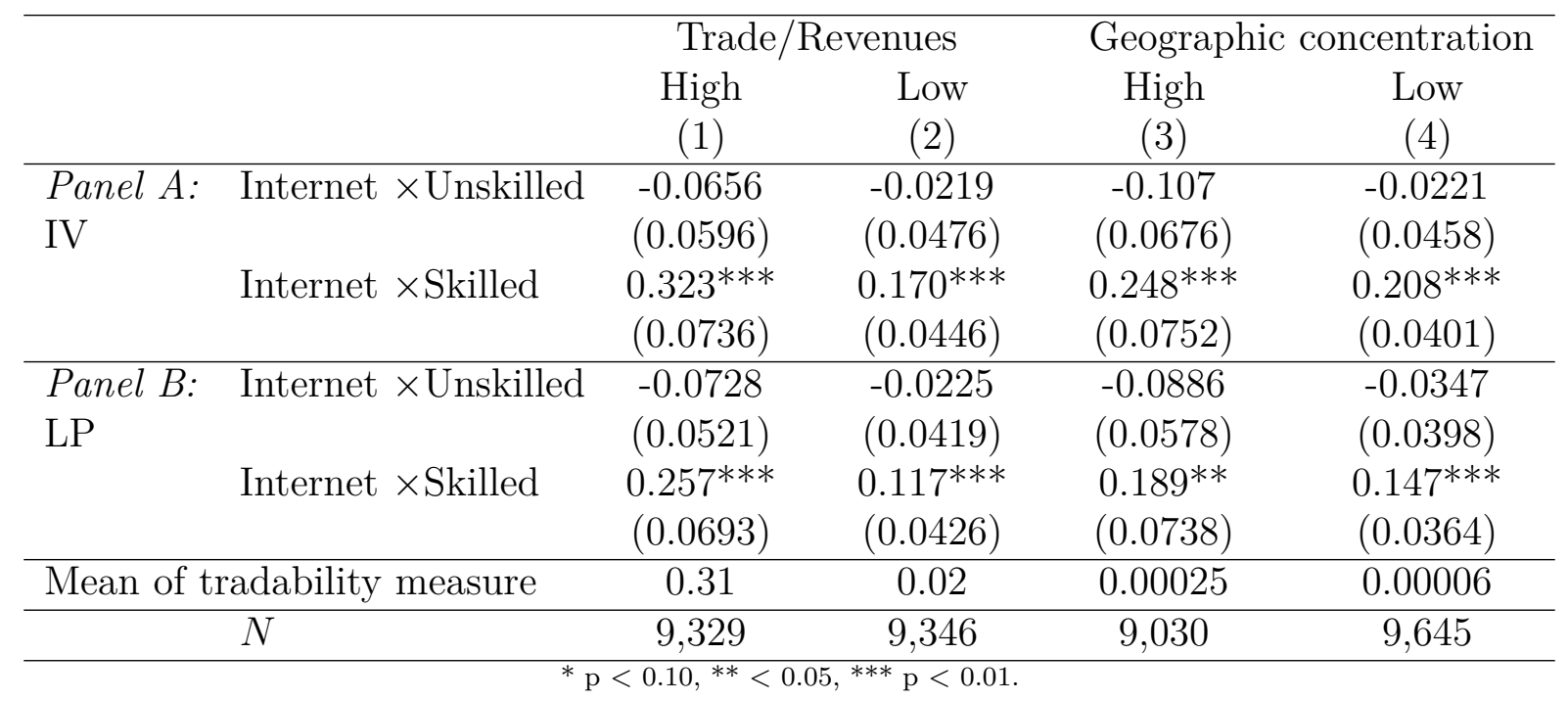

Note: Baseline firm sample over the period 2001-2007, consisting of 18,675 joint-stock firms recorded in the internet survey. Sampling weights are used to ensure representative results for the population of joint-stock firms. (Un)Skilled comprises workers with(out) high school diploma. The standard errors are clustered at the municipality level and robust to heteroskedasticity. All regressions include fixed effect for year, municipality and industry. We use two measures of tradability. In Columns (1) and (2), we measure tradability in each 4-digit industry by dividing total levels of exports and imports by the value added of firms. In Columns (3) og (4), we follow Jensen and Kletzer (2005) in measuring tradability by the geographic concentration of an industry, defined as the Herfindahl index of employment shares across municipalities in each 4-digit industry. For both measures, we estimate the production function separately for firms in industries with values of tradability above and below the median in the baseline firm sample. 


\section{Appendix B: Estimation details}

By simultaneous estimation of equations (4) and (7), we obtain consistent estimates of $\beta_{u 0}$, $\beta_{s 0}, \beta_{k 1}, \beta_{u 1}, \beta_{s 1}$, and $\Phi_{t}\left(a_{i m k t}, k_{i m k t}\right)=\beta_{k 0} k_{i m k t}+\omega_{t}\left(a_{i m k t}, k_{i m k t}\right)$. While these output elasticities are sufficient to assess how broadband adoption affects labor productivity, we need to identify $\beta_{k 0}$ to recover the full shift in production technology. Because $k_{i m k t}$ is colinear with the non-parametric function $\omega_{t}\left(a_{i m k t}, k_{i m k t}\right)$, further assumptions are necessary.

Assuming that $\omega_{i m k t}$ follows a first-order Markow process, we can write

$$
\omega_{i m k t}=E\left[\omega_{i m k t} \mid \omega_{i m k t-1}\right]+\xi_{i m k t} .
$$

This simply decomposes $\omega_{\text {imkt }}$ into its conditional expectation at time $t-1, E\left[\omega_{\text {imkt }} \mid \omega_{\text {imkt-1 }}\right]$, and a deviation from that expectation, $\xi_{i m k t}$. If the capital stock is pre-determined and current investment (which will react to productivity shocks) takes one period before it comes productive, it follows that

$$
E\left[\xi_{\text {imkt }} k_{\text {imkt }}\right]=0 .
$$

This is the moment which LP use to identify the capital coefficient. Roughly speaking, variation in $k_{i m k t}$ conditional on $\omega_{i m k t-1}$ is the exogenous variation used for identification. To operationalize this approach in a GMM context, note that given a guess on the capital coefficient $\beta_{k 0}$, we can rewrite unobserved productivity as

$$
\omega_{i m k t}\left(\beta_{k 0}\right)=\hat{\Phi}_{i m k t}-\beta_{k 0} k_{i m k t}
$$

Given these $\omega_{i m k t}\left(\beta_{k 0}\right)$, we compute $\xi_{\text {imkt }}$ by non-parametrically regressing $\omega_{i m k t}\left(\beta_{k 0}\right)$ 's on $\omega_{i m k t-1}\left(\beta_{k o}\right)$ 's and a constant term; we then form the residual

$$
\xi_{i m k t}\left(\beta_{k 0}\right)=\omega_{i m k t}\left(\beta_{k 0}\right)-\hat{\Psi}\left(\omega_{i m k t-1}\left(\beta_{k 0}\right)\right)
$$

where $\hat{\Psi}\left(\omega_{\text {imkt-1 }}\left(\beta_{k 0}\right)\right)$ are predicted values from the non-parametric regression.

The $\xi_{i m k t}\left(\beta_{k 0}\right)$ 's are used to form a sample analogue to the above moment. i.e.

$$
\frac{1}{T} \frac{1}{N} \sum_{t} \sum_{i} \xi_{i m k t}\left(\beta_{k 0}\right) \cdot k_{i m k t} .
$$

We estimate $\beta_{k 0}$ by minimizing the GMM criterion function

$$
Q\left(\beta_{k 0}\right)=\min _{\beta_{k 0}}\left(\frac{1}{N} \frac{1}{T_{i 1}} \sum_{i} \sum_{t=T_{i 0}}^{T_{i 1}} \xi_{i m k t}\left(\beta_{k 0}\right) \cdot k_{i m k t}\right)^{2}
$$


where $i$ indexing firms and $T_{i 0}$ and $T_{i 1}$ index the second and last period in which firm $i$ is observed.

Because our baseline sample is a repeated cross-section (rather than panel data), we adjust the above estimation procedure. Exploiting the random sampling of firms, we can identify $\beta_{k 0}$ from the moment

$$
E\left[\bar{\xi}_{m k t}, \bar{k}_{m k t}\right]=0 \text {. }
$$

where the municipality average of a variable is denoted by upper bar. By applying the above procedure to our panel data at the municipality level, we obtain the GMM criterion function

$$
Q\left(\beta_{k 0}\right)=\min _{\beta_{k 0}}\left(\frac{1}{M} \frac{1}{T_{m 1}} \sum_{m} \sum_{t=T_{m 0}}^{T_{m 1}} \sqrt{N_{m k t}} \bar{\xi}_{m k t}\left(\beta_{k 0}\right) \cdot \bar{k}_{m k t}\right)^{2}
$$

where $T_{m 0}$ and $T_{m 1}$ index the second and last period municipality $m$ is observed and $N_{m k t}$ is the number of firms in municipality $m$ in period $t$. To obtain standard errors on $\beta_{k 0}$ in Table 2, we use bootstrap while clustering by municipality. 